\title{
Solid formulation of a supersaturable self-microemulsifying drug delivery system for valsartan with improved dissolution and bioavailability
}

\author{
Dong Woo Yeom ${ }^{1, *}$, Bo Ram Chae ${ }^{1,2, *}$, Jin Han Kim ${ }^{1}$, Jun Soo Chae ${ }^{1}$, Dong Jun Shin ${ }^{1}$, \\ Chang Hyun Kim ${ }^{1}$, Sung Rae Kim${ }^{1}$, Ji Ho Choi ${ }^{1}$, Seh Hyon Song ${ }^{2}$, Dongho Oh${ }^{2}$, Se Il \\ Sohn ${ }^{2}$ and Young Wook Choi ${ }^{1}$ \\ ${ }^{1}$ College of Pharmacy, Chung-Ang University, Seoul 06974, Republic of Korea \\ ${ }^{2}$ Daewon Pharm. Co., Ltd, Seoul 04994, Republic of Korea \\ *These authors have contributed equally to this work \\ Correspondence to: Young Wook Choi, email: ywchoi@cau.ac.kr \\ Keywords: valsartan; SMEDDS; solid carrier; tablet; optimization \\ Received: June 27, $2017 \quad$ Accepted: September 20, 2017 \\ Published: October 09, 2017 \\ Copyright: Yeom et al. This is an open-access article distributed under the terms of the Creative Commons Attribution License 3.0 \\ (CC BY 3.0), which permits unrestricted use, distribution, and reproduction in any medium, provided the original author and source \\ are credited.
}

\section{ABSTRACT}

In order to improve the dissolution and oral bioavailability of valsartan (VST), and reduce the required volume for treatment, we previously formulated a supersaturable self-microemulsifying drug delivery system (SuSMEDDS) composed of VST (80 mg), Capmul ${ }^{\circledR}$ MCM (13.2 mg), Tween ${ }^{\circledR} 80$ (59.2 mg), Transcutol ${ }^{\circledR}$ P (59.2 mg), and Poloxamer 407 (13.2 mg). In the present study, by using Florite ${ }^{\circledR}$ PS-10 (119.1 $\mathrm{mg})$ and Vivapur ${ }^{\circledR} 105(105.6 \mathrm{mg})$ as solid carriers, VST-loaded solidified SuSMEDDS (S-SUSMEDDS) granules were successfully developed, which possessed good flow properties and rapid drug dissolution. By introducing croscarmellose sodium (31 mg) as a superdisintegrant, S-SuSMEDDS tablets were also successfully formulated, which showed fast disintegration and high dissolution efficiency. Preparation of granules and tablets was successfully optimized using D-optimal mixture design and 3-level factorial design, respectively, resulting in percentage prediction errors of $<\mathbf{1 0} \%$. In pharmacokinetic studies in rats, the relative bioavailability of the optimized granules was $107 \%$ and $222 \%$ of values obtained for SuSMEDDS and Diovan ${ }^{\circledR}$ powder, respectively. Therefore, we conclude that novel S-SuSMEDDS formulations offer great potential for developing solid dosage forms of a liquefied formulation such as SuSMEDDS, while improving oral absorption of drugs with poor water solubility.

\section{INTRODUCTION}

Use of a self-microemulsifying drug delivery system (SMEDDS) is widely known as one of the most effective approaches to overcome problems associated with low solubility and poor oral absorption of water-insoluble drugs. Previously, we have demonstrated that a supersaturable SMEDDS (SuSMEDDS) greatly contributed to enhanced dissolution and oral absorption of valsartan (VST), a drug with poor solubility in water [1]. However, the liquid state of both SMEDDS and SuSMEDDS causes several limitations for practical manufacturing development and clinical application. Since the liquid formulation is generally required to be enclosed in soft gelatin capsules, problems are frequently evoked, including high manufacturing costs, pharmaceutical incompatibility, drug leakage or precipitation, and capsule ageing [2]. In recent years, much attention has been focused on solidification of these liquid systems, with particular emphasis on introducing inert solid pharmaceutical excipients [3-7].

Various types of solid carriers have been extensively investigated to solidify SMEDDS, including silica-based 
water-insoluble adsorbents (e.g., porous silica, magnesium aluminometasilicate, and calcium silicate), cellulosebased hydrophilic diluents (e.g., microcrystalline cellulose, hydroxypropyl cellulose, and low-substituted hydroxypropyl cellulose), and saccharide-based watersoluble diluents (e.g., maltodextrin, lactose, and starch) [7-11]. Although adsorbents with high oil-absorbing capacity minimize the quantity required to solidify the SMEDDS, incomplete desorption of SMEDDS components may occur due to hydrophobic interactions between the drug and adsorbents [8]. Diluents generally possess lower oil-absorbing capacities than adsorbents, but could allow complete desorption of SMEDDS components $[7,9]$. Therefore, a suitable combination of adsorbent and diluent is desirable for developing a solidified SMEDDS, while minimizing the total mass and enhancing drug dissolution. However, until now, no attempts have been made to simultaneously use both adsorbents and diluents for the solidification of SMEDDS.

For developing tablet dosage forms, choice of components and compaction procedure is important. In particular, the role of disintegrating agents is crucial in the formulation of solidified SMEDDS preparations that can rapidly disintegrate and spontaneously emulsify in gastric or intestinal fluid [4, 6]. Solidified tablets containing croscarmellose sodium or Kollidon ${ }^{\circledR}$ CL-SF as a disintegrant showed maximum drug release of over $90 \%$ within $30 \mathrm{~min}$, whereas tablets without disintegrant resulted in poor drug release of less than $5 \%$ after $2 \mathrm{~h}$ $[2,6]$. Nano- or micro-particles of solid carrier can also induce greater compaction, thus retarding disintegration [12]. Superdisintegrants such as croscarmellose sodium (CS), sodium starch glycolate (SSG), and Kollidon ${ }^{\circledR} \mathrm{CL}$ (KC) have been used in tablet formulation, resulting in good disintegration characteristics $[2,6,13]$. Compression force can also affect the performance of disintegrants. Increased compression force results in increased tablet hardness, thus delaying disintegration [14-16].

The present study was performed to develop a solidified dosage form of VST-containing SuSMEDDS (S-SuSMEDDS), to take advantage of improved drug dissolution and oral absorption properties afforded by solidification of the liquid formulation. First, solid carriers (either adsorbents or diluents) were screened based on solidifying behavior and desorption characteristics. Solidification was then optimized, combining the two solid carriers to obtain S-SuSMEDDS granules by using D-optimal mixture design. Second, S-SuSMEDDS tablets were prepared by direct compression of a mixture of S-SuSMEDDS granules and various superdisintegrants. The tableting procedure was optimized using 3-level factorial design (3-LFD), involving compression force, and the concentration and type of superdisintegrant. Finally, in addition to a dissolution comparison, in vivo pharmacokinetic (PK) assessments were carried out in rats.

\section{RESULTS AND DISCUSSION}

Previously, we demonstrated that a supersaturable SMEDDS (SuSMEDDS) formulation greatly improved the dissolution and oral bioavailability of VST, while reducing the total volume required for treatment [1]. In the present study, the development of a solidified SuSMEDDS (S-SuSMEDDS) will be discussed in terms of solid carrier screening, optimization of solid formulation, in vitro characterization including dissolution, and in vivo $\mathrm{PK}$ evaluation.

\section{Solid carrier selection}

To develop a solidified formulation of SuSMEDDS, selection of a suitable solid carrier is a key for effective adsorption and absorption of the liquid components. Different types of solid carriers have varied characteristics, such as differences in particle size, pore size, specific surface area, and oil-absorption capacity, thereby affecting the solidification of SuSMEDDS. In this experiment, various types of solid carrier were screened: Sylysia ${ }^{\circledR}$ 350, Neusilin ${ }^{\circledR}$ US2, and Florite ${ }^{\circledR}$ PS-10 as silica-based adsorbents, owing to their small particle size, high surface area, uniform porous structure, and high oil-absorption capacity; Vivapur $^{\circledR} 105$, hydroxypropyl cellulose L type (HPC), and low-substituted hydroxypropyl cellulose B1 (L-HPC) as cellulose-based diluents, owing to their relatively hydrophilic and viscous properties; and Starch $^{\circledR} 1500$, lactose monohydrate, and maltodextrin as saccharide-based diluents, as they are water-soluble and often used in commercial products.

Figure 1 represents the flow properties of the solidified mass in terms of Carr's index (CI) against the ratio of solid carrier to SuSMEDDS. Flow properties of all of the S-SuSMEDDS increased as the ratio of solid carrier to SuSMEDDS increased. USP guidelines classify the flow property in terms of CI values, as excellent (1$10)$, good (11-15), fair (16-20), passable (21-25), and poor $(>26)$ [17]. CI values for all of the S-SuSMEDDS were observed within the range of $9.2-18.8 \%$, indicating that SuSMEDDS were suitably absorbed into the solid carriers, and thus the resultant S-SuSMEDDS showed fair to excellent free-flowing properties. Solidifying behavior was further evaluated by critical solidifying ratio (CSR), a critical value representing constant free-flow, as listed in Table 1. The following values were observed, in order: silica-based adsorbents $(0.4-0.5)>$ cellulose-based diluents (1.7-2.7) > saccharide-based diluents (3.6-6.0), demonstrating superior SuSMEDDS-absorption capacities of adsorbents compared to diluents. Saccharide-based diluents showed inferior solidifying properties compared with cellulose-based diluents and silica-based adsorbents, in which hydrophobic interactions and/or van der Waals forces between solid carriers and SuSMEDDS may play an important role for solidification [18]. Moreover, CSR 
values for silica-based adsorbents were much lower than those of cellulose-based diluents. Since silica-based adsorbents have a mesoporous structure and intra-particle air spaces (void volume), they potentially provide a greater surface area for SuSMEDDS contact compared with cellulose-based diluents, thus absorbing a higher quantity of SuSMEDDS. Among the adsorbents, Florite ${ }^{\circledR}$ PS-10 showed the lowest CSR value, and could therefore be a promising candidate for solid carrier selection.

Drug content and droplet size upon reconstitution of the VST-loaded solidified mass are listed in Table 1. The drug content of all preparations was in the range of $93-105 \%$, suggesting that the VST-containing SuSMEDDS was efficiently absorbed onto the solid carriers. Droplet size was observed to be in the range of 120.0-168.1 nm for all preparations. These sizes are very close to those observed for SuSMEDDS $(187.8 \pm 5.5$ $\mathrm{nm})$, as reported previously [1]. It was therefore expected that the components of the SuSMEDDS such as oil, surfactant, co-surfactant, and supersaturating agent could be amply desorbed from solid carriers into the medium, thus maintaining the characteristics of the SuSMEDDS. Solid carrier type did not appear to impact reconstitution properties.

The dissolution efficiency (DE) values of various solidified masses were evaluated in $\mathrm{pH} 1.2$ medium to support solid carrier selection, and the results suggested a dependence on solid carrier type. DE values were as follows, in order: cellulose-based diluents (55.4-66.3\%) $>$ saccharide-based diluents (48.1-50.4\%) > silica-based adsorbents (40.6-46.5\%). In comparison to DE values measured for SuSMEDDS $(53.6 \pm 3.1 \%)$, values observed for silica-based adsorbents were considerably lower. This may have been due to the formation of hydrogen bonds between the hydroxyl group of VST and the silanol moiety on the surface of silica-based adsorbents. In contrast, cellulose-based diluents showed slightly higher DE values than SuSMEDDS. The porous structure of cellulose-based diluents may have caused entrapment of SuSMEDDS within the pores, thereby stabilizing the S-SuSMEDDS formulation by inhibiting recrystallization of the drug $[19,20]$. In addition, the cellulose-based diluents may have gradually desorbed the components of SuSMEDDS into the medium, thereby enhancing the fine dispersion of SuSMEDDS droplets. The most effective cellulose-based solid carrier for increasing drug release was Vivapur ${ }^{\circledR}$ 105, followed by L-HPC and HPC. This corresponds with particle size: Vivapur ${ }^{\circledR} 105(10 \mu \mathrm{m})<$ L-HPC $(50$ $\mu \mathrm{m})<$ HPC $(<850 \mu \mathrm{m})$. As particle size decreases, the solid carrier disperses more evenly, increasing the surface area in the dissolution medium [21]. Florite ${ }^{\circledR}$ PS-10 and Vivapur $^{\circledR} 105$ showed the highest DE values for the adsorbents and diluents, respectively. It is noteworthy that the adsorbents render high oil-absorbing capacity with incomplete desorption, but the diluents render low oilabsorbing capacity with complete desorption $[7,8]$. Thus, in consideration of mutual compensation, a mixed solid carrier, composed of both Florite ${ }^{\circledR}$ PS-10 and Vivapur ${ }^{\circledR}$ 105 , was selected for further optimization of solidification.

\section{Optimization and characterization of S-SuSMEDDS granule}

D-optimal mixture design was applied to determine the optimal mixture of the two solid carriers, for minimizing the total mass of the final S-SuSMEDDS granules, while maximizing the oral absorption of VST. Florite $^{\circledR}$ PS-10 (X $\left.; \mathrm{mg}\right)$ and Vivapur ${ }^{\circledR} 105\left(\mathrm{X}_{2} ; \mathrm{mg}\right)$ were the independent variables, as listed in Table 2 . The CSR $\left(\mathrm{Y}_{1} ; \mathrm{g} / \mathrm{mL}\right)$ and percentage of drug released in 15 $\min \left(\mathrm{D}_{15}, \mathrm{Y}_{2} ; \%\right)$ were introduced as response variables, due to their crucial roles in determining the absorption and desorption capacity of the solid carrier from the S-SuSMEDDS formulation. As shown in Table 3, for the eight experimental runs, $\mathrm{Y}_{1}$ and $\mathrm{Y}_{2}$ were in the ranges of $0.42-1.8 \mathrm{~g} / \mathrm{mL}$ and $45.7-64.3 \%$, respectively. Statistical parameters analyzed using Design-Expert software are listed in Table 4. As all responses were simultaneously fitted to linear, quadratic, and cubic models, the linear model was selected as the best fitting mathematical model for both $\mathrm{Y}_{1}$ and $\mathrm{Y}_{2}$. Sequential p-values for $\mathrm{Y}_{1}$ and $\mathrm{Y}_{2}$ were $<0.01$, indicating that the effects of the responses were statistically significant up to a $99 \%$ confidence level. The lack of fit $\mathrm{p}$-values of the responses $\mathrm{Y}_{1}$ and $\mathrm{Y}_{2}$ were > 0.1 , suggesting an adequate model fit [22]. All squared correlation coefficient $\left(\mathrm{R}^{2}\right)$ and adjusted $\mathrm{R}^{2}$ values for $\mathrm{Y}_{1}$ and $\mathrm{Y}_{2}$ were $>95 \%$, indicating satisfactory analysis quality. Based upon the results obtained from the multiple linear regression analysis for each response variable, the model equations were generated as follows:

$$
\begin{aligned}
& Y_{1}=0.0042 X_{1}+0.018 X_{2} \\
& Y_{2}=0.467 X_{1}+0.636 X_{2}
\end{aligned}
$$

The interaction term $\left(\mathrm{X}_{1} \mathrm{X}_{2}\right)$ was not observed in the above model equations, suggesting that there was no significant interaction effect between $\mathrm{X}_{1}$ and $\mathrm{X}_{2}$ on $\mathrm{Y}_{1}$ and $\mathrm{Y}_{2}$. The similar particle sizes of $\mathrm{X}_{1}$ and $\mathrm{X}_{2}\left(\right.$ Florite $^{\circledR}$ PS-10, $10 \mu \mathrm{m}$; Vivapur $^{\circledR} 105,15 \mu \mathrm{m}$ ) may have formed a homogeneous mixture of $\mathrm{X}_{1}$ and $\mathrm{X}_{2}$, permitting equal absorption of SuMEDDS into either $X_{1}$ or $X_{2}$. Figure $2 \mathrm{~A}$ shows the effects of $X_{1}$ and $X_{2}$ on the responses. As $X_{1}$ increased and $X_{2}$ decreased, both the CSR value $\left(\mathrm{Y}_{1}\right)$ and $\mathrm{D}_{15}\left(\mathrm{Y}_{2}\right)$ constantly decreased in the ranges of $1.8-0.4 \mathrm{~g} / \mathrm{mL}$ and $64.3-45.7 \%$, respectively. As expected, $\mathrm{X}_{1}$ may reduce the quantity required for solidifying the SuSMEDDS, but adversely affects the dissolution rate of VST, compared with $\mathrm{X}_{2}$. These data indicated that each solid carrier maintained physiochemical properties to absorb and desorb the components of SuSMEDDS, even though the SuSMEDDS was homogenously absorbed into the mixtures of $X_{1}$ and $X_{2}$.

The independent variables were simultaneously optimized for responses using the desirability function. 


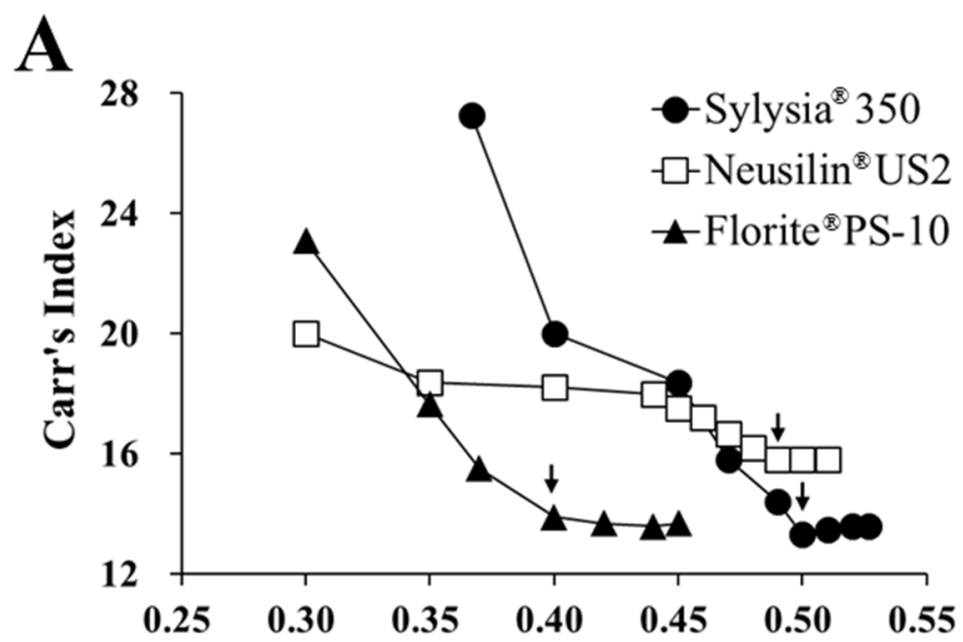

B
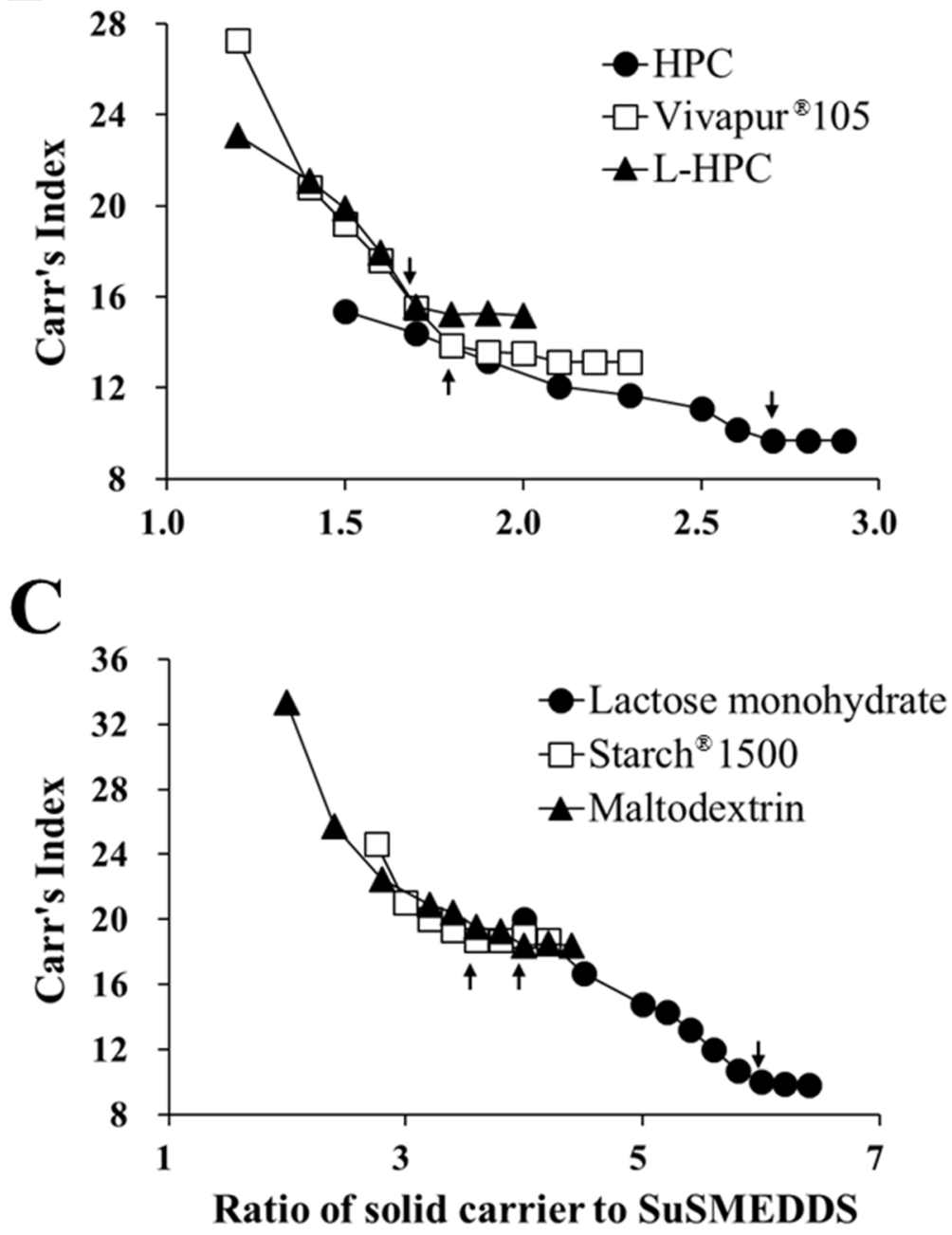

Figure 1: Flow property changes in the S-SuSMEDDS formulation against the ratio of solid carriers to SuSMEDDS. Arrow indicates the critical point representing a constant flow property (CSR). (A) Silica-based adsorbents. (B) Cellulose-based diluents. (C) Saccharide-based diluents. 
Table 1: Solid carrier screening for the solidification of SuSMEDDS

\begin{tabular}{|c|c|c|c|c|c|c|c|c|c|}
\hline & \multicolumn{3}{|c|}{ Silica-based adsorbents } & \multicolumn{3}{|c|}{ Cellulose-based diluents } & \multicolumn{3}{|c|}{ Saccharide-based diluents } \\
\hline & Sylysia $^{\circledR} 350$ & Neusilin ${ }^{\circledR}$ US2 & $\begin{array}{c}\text { Florite }^{\circledR} \\
\text { PS-10 }\end{array}$ & HPC & Vivapur $^{\circledR} 105$ & L-HPC & Lactose & $\operatorname{Starch}^{\circledR} 1500$ & Maltodextrin \\
\hline \multicolumn{10}{|l|}{ Composition (mg) } \\
\hline SuSMEDDS $^{\mathrm{a}}$ & 224.8 & 224.8 & 224.8 & 224.8 & 224.8 & 224.8 & 224.8 & 224.8 & 224.8 \\
\hline Solid carrier & 112.3 & 110.1 & 89.9 & 606.6 & 404.4 & 381.9 & 1347.9 & 808.7 & 898.6 \\
\hline Total & 337.1 & 334.9 & 314.7 & 831.4 & 629.2 & 606.7 & 1572.7 & 1033.5 & 1123.4 \\
\hline \multicolumn{10}{|c|}{ Physical characteristics $^{b}$} \\
\hline Droplet size (nm) & $147.7 \pm 9.1$ & $120.0 \pm 7.1$ & $146.4 \pm 1.1$ & $130.5 \pm 4.4$ & $151.9 \pm 9.4$ & $168.1 \pm 8.2$ & $151.5 \pm 3.6$ & $145.6 \pm 2.2$ & $121.2 \pm 56.6$ \\
\hline PDI & $0.36 \pm 0.05$ & $0.41 \pm 0.05$ & $0.42 \pm 0.11$ & $0.57 \pm 0.09$ & $0.21 \pm 0.03$ & $0.47 \pm 0.05$ & $0.52 \pm 0.55$ & $0.49 \pm 0.06$ & $0.74 \pm 0.07$ \\
\hline Drug content $(\%)$ & $93.7 \pm 1.0$ & $94.5 \pm 2.5$ & $94.1 \pm 3.1$ & $101.4 \pm 6.6$ & $98.6 \pm 4.0$ & $102.4 \pm 2.6$ & $99.6 \pm 5.6$ & $104.9 \pm 3.4$ & $98.2 \pm 2.9$ \\
\hline CSR (g/mL) & 0.5 & 0.49 & 0.4 & 2.7 & 1.8 & 1.7 & 6 & 3.6 & 4 \\
\hline $\mathrm{DE}(\%)^{\mathrm{c}}$ & $40.6 \pm 2.5$ & $46.3 \pm 1.7$ & $46.5 \pm 2.5$ & $56.3 \pm 1.6$ & $66.3 \pm 2.1$ & $55.4 \pm 0.5$ & $48.1 \pm 1.1$ & $48.9 \pm 2.1$ & $50.4 \pm 2.8$ \\
\hline
\end{tabular}

${ }^{a}$ SuSMEDDS composed of VST (80 mg), Capmul ${ }^{\circledR}$ MCM (13.2 mg), Tween ${ }^{\circledR} 80$ (59.2 mg), Transcutol ${ }^{\circledR}$ P (59.2 mg), and Poloxamer 407 (13.2 mg) was formulated based on the earlier report [1]. ${ }^{b}$ Values are presented as the mean $\pm \mathrm{SD}(\mathrm{n}=3)$. ${ }^{\mathrm{c}}$ Dissolution efficiency (DE) was calculated using the trapezoidal rule as follows: $\mathrm{DE}(\%)=\left[\int_{1}^{\mathrm{t} 2} \mathrm{ydt} / \mathrm{y}_{100}(\mathrm{t} 2-\mathrm{t} 1)\right] \times 100$, where $\mathrm{y}$ is the percentage of dissolved product [42].

Abbreviations: SuSMEDDS, supersaturable self-microemulsifying drug delivery system; HPC, hydroxypropyl cellulose; L-HPC, low-substituted hydroxypropyl cellulose; PDI, polydispersity index; CSR, critical solidifying ratio.

Table 2: Variables used for the optimization of S-SuSMEDDS granules and tablets, using D-optimal mixture design and 3-LFD, respectively

\begin{tabular}{|c|c|c|c|c|c|c|c|}
\hline \multirow[t]{2}{*}{ Type } & \multicolumn{5}{|c|}{ Variables } & \multicolumn{2}{|c|}{ Responses } \\
\hline & Formulation variables & & Lev & l used & & Response variables & Target \\
\hline \multirow{2}{*}{ S-SuSMEDDS granules } & $\mathrm{X}_{1}=$ Florite $^{\circledR}$ PS-10(\%) & & 0 & 100 & & $\mathrm{Y}_{1}=\mathrm{CSR}(\mathrm{g} / \mathrm{mL})$ & Minimize \\
\hline & $X_{2}=\operatorname{Vivapur}^{\circledR} 105(\%)$ & & 0 & 100 & & $\mathrm{Y}_{2}=\mathrm{D}_{15}(\%)$ & Maximize \\
\hline \multirow{4}{*}{ S-SuSMEDDS tablets } & $\mathrm{X}_{1}=$ Compression force $(\mathrm{kgf})$ & 500 & & 1250 & 2000 & $\mathrm{Y}_{1}=\operatorname{Hardness}(\mathrm{N})$ & $>50$ \\
\hline & $\begin{array}{l}X_{2}=\text { Concentration of } \\
\text { superdisintegrant }(\%)\end{array}$ & 2 & & 5 & 8 & $Y_{2}=\operatorname{Disint} \%(\%)$ & Maximize \\
\hline & $\mathrm{X}_{3}=$ Type of superdisintegrant & $\mathrm{CS}$ & & $\mathrm{KC}$ & SSG & $\mathrm{Y}_{3}=\mathrm{DE}(\%)$ & Maximize \\
\hline & & & & & & $\mathrm{Y}_{4}=$ Total mass $(\mathrm{mg})$ & Minimize \\
\hline
\end{tabular}

Abbreviations: S-SuSMEDDS, solidified supersaturable self-microemulsifying drug delivery system; 3-LFD, 3-level factorial design; CSR, critical solidifying ratio; $\mathrm{D}_{15}$, percentage of drug released in $15 \mathrm{~min}$; Disint $\%$, percentage of disintegration in 30 min; DE, dissolution efficiency; CS, croscarmellose sodium; KC, Kollidon ${ }^{\circledR}$ CL; SSG, Sodium starch glycolate.

As shown in Table 2, $\mathrm{Y}_{1}$ was set to be minimized, whereas $Y_{2}$ was set to be maximized. The optimized amounts of Florite ${ }^{\circledR}$ PS-10 $\left(\mathrm{X}_{1}\right)$ and Vivapur ${ }^{\circledR} 105\left(\mathrm{X}_{2}\right)$ were $53 \%$ and $47 \%$, respectively, with a corresponding desirability value of 0.502. Predicted and experimental values were compared to determine the accuracy of prediction, using percentage prediction error (Table 5). The calculated percentage prediction errors were low $(<10 \%)$, indicating that the D-optimal mixture design used to optimize the composition of mixed solid carriers was accurate and reliable. 
Table 3: Composition and observed responses from runs

\begin{tabular}{|c|c|c|c|c|c|c|c|}
\hline \multirow[t]{2}{*}{ Mixture number } & \multicolumn{3}{|c|}{ Formulation composition } & \multicolumn{4}{|c|}{ Response measured } \\
\hline & $\mathrm{X}_{1}$ & $\mathbf{X}_{2}$ & $\mathbf{X}_{3}$ & $Y_{1}$ & $\mathbf{Y}_{2}$ & $\mathbf{Y}_{3}$ & $\mathbf{Y}_{4}$ \\
\hline \multicolumn{8}{|c|}{ (A) Optimized S-SuSMEDDS granules } \\
\hline & $\begin{array}{c}\text { Florite }^{\circledR} \text { PS- } \\
10(\%)\end{array}$ & $\begin{array}{c}\text { Vivapur }^{\circledR} 105 \\
(\%)\end{array}$ & N.A. ${ }^{a}$ & CSR $(g / m L)$ & $\mathrm{D}_{15}(\%)$ & N.A. & N.A. \\
\hline 1 & 0 & 100 & - & 1.8 & 64.3 & - & - \\
\hline 2 & 25 & 75 & - & 1.45 & 59.3 & - & - \\
\hline 3 & 50 & 50 & - & 1.1 & 55.5 & - & - \\
\hline 4 & 75 & 25 & - & 0.8 & 52.7 & - & - \\
\hline 5 & 100 & 0 & - & 1.4 & 46.6 & - & - \\
\hline 6 & 0 & 100 & - & 1.8 & 62.8 & - & - \\
\hline 7 & 50 & 50 & - & 1.15 & 54.4 & - & - \\
\hline 8 & 100 & 0 & - & 0.42 & 45.7 & - & - \\
\hline \multicolumn{8}{|c|}{ (B) Optimized S-SuSMEDDS tablets } \\
\hline & $\begin{array}{l}\text { Compression } \\
\text { force }(\%)\end{array}$ & $\begin{array}{l}\text { Conc. of super- } \\
\text { disintegrant } \\
(\%)\end{array}$ & $\begin{array}{l}\text { Type of super- } \\
\text { disintegrant }\end{array}$ & Hardness $(\mathrm{N})$ & Disint $(\%)$ & $\begin{array}{l}\mathrm{DE} \\
(\%)\end{array}$ & $\begin{array}{l}\text { Total mass } \\
\quad(\mathrm{mg})\end{array}$ \\
\hline 1 & 500 & 2 & $\mathrm{CS}$ & 77 & 23.8 & 3.4 & 466.1 \\
\hline 2 & 1250 & 2 & $\mathrm{CS}$ & 93 & 23.0 & 3.3 & 465.5 \\
\hline 3 & 2000 & 2 & $\mathrm{CS}$ & 66 & 23.0 & 3.1 & 466.2 \\
\hline 4 & 500 & 5 & $\mathrm{CS}$ & 76 & 89.2 & 27.3 & 478.2 \\
\hline 5 & 1250 & 5 & $\mathrm{CS}$ & 72 & 84.9 & 28.8 & 480.5 \\
\hline 6 & 2000 & 5 & $\mathrm{CS}$ & 73 & 87.2 & 28.8 & 476.6 \\
\hline 7 & 500 & 8 & $\mathrm{CS}$ & 75 & 100.0 & 38.6 & 489.6 \\
\hline 8 & 1250 & 8 & CS & 77 & 100.0 & 39.5 & 489.7 \\
\hline 9 & 2000 & 8 & $\mathrm{CS}$ & 71 & 100.0 & 38.9 & 493.1 \\
\hline 10 & 500 & 2 & $\mathrm{KC}$ & 74 & 16.9 & 3.8 & 464.3 \\
\hline 11 & 1250 & 2 & $\mathrm{KC}$ & 81 & 18.3 & 4.3 & 461.8 \\
\hline 12 & 2000 & 2 & $\mathrm{KC}$ & 69 & 19.1 & 5.3 & 466.5 \\
\hline 13 & 500 & 5 & $\mathrm{KC}$ & 80 & 63.8 & 32.2 & 476.3 \\
\hline 14 & 1250 & 5 & $\mathrm{KC}$ & 88 & 59.8 & 33.8 & 479.3 \\
\hline 15 & 2000 & 5 & $\mathrm{KC}$ & 82 & 62.6 & 31.7 & 480.5 \\
\hline 16 & 500 & 8 & $\mathrm{KC}$ & 74 & 89.5 & 42.8 & 493.8 \\
\hline 17 & 1250 & 8 & $\mathrm{KC}$ & 84 & 90.1 & 41.3 & 490.2 \\
\hline 18 & 2000 & 8 & $\mathrm{KC}$ & 80 & 92.0 & 40.6 & 489.9 \\
\hline 19 & 500 & 2 & SSG & 68 & 23.8 & 4.5 & 461.3 \\
\hline 20 & 1250 & 2 & SSG & 86 & 27.3 & 4.8 & 463.7 \\
\hline 21 & 2000 & 2 & SSG & 69 & 26.4 & 4.8 & 465.8 \\
\hline
\end{tabular}




\begin{tabular}{|c|c|c|c|c|c|c|c|}
\hline \multirow[t]{2}{*}{ Mixture number } & \multicolumn{3}{|c|}{ Formulation composition } & \multicolumn{4}{|c|}{ Response measured } \\
\hline & $\mathrm{X}_{1}$ & $\mathrm{X}_{2}$ & $X_{3}$ & $Y_{1}$ & $Y_{2}$ & $Y_{3}$ & $\mathbf{Y}_{4}$ \\
\hline 22 & 500 & 5 & SSG & 67 & 41.1 & 12.1 & 476.1 \\
\hline 23 & 1250 & 5 & SSG & 79 & 44.1 & 12.3 & 479.3 \\
\hline 24 & 2000 & 5 & SSG & 66 & 49.0 & 11.7 & 480.2 \\
\hline 25 & 500 & 8 & SSG & 76 & 68.6 & 25.7 & 489.3 \\
\hline 26 & 1250 & 8 & SSG & 88 & 69.2 & 25.6 & 491.7 \\
\hline 27 & 2000 & 8 & SSG & 70 & 71.1 & 27.4 & 493.2 \\
\hline 28 & 1250 & 5 & $\mathrm{CS}$ & 76 & 80.1 & 30.1 & 478.6 \\
\hline 29 & 1250 & 5 & $\mathrm{KC}$ & 82 & 64.4 & 35.6 & 479.8 \\
\hline 30 & 1250 & 5 & SSG & 83 & 48.8 & 26.1 & 476.5 \\
\hline
\end{tabular}

${ }^{a}$ Not applicable

Abbreviations: S-SuSMEDDS, solidified supersaturable self-microemulsifying drug delivery system; CSR, critical solidifying ratio; $\mathrm{D}_{15}$, percentage of drug released in $15 \mathrm{~min}$; Disint $\%$, percentage of disintegration in $30 \mathrm{~min}$; DE, dissolution efficiency; CS, croscarmellose sodium; KC, Kollidon ${ }^{\circledR}$ CL; SSG, Sodium starch glycolate.

As shown in Figure 3A, scanning electron microscopy (SEM) images exhibited the morphologies of VST, two solid carriers, and optimized S-SuSMEDDS granules. VST as a raw material appeared to have a rough and rectangular-shaped crystalline structure [23]. Solid carriers were identified as aggregates of particles. No rectangular crystals of VST were observed on the surface of the optimized S-SuSMEDDS granule, indicating that VST-loaded SuSMEDDS was completely absorbed onto the solid carriers. To identify the crystalline state of VST in the solidified formulation, differential scanning calorimetry (DSC) was performed. DSC thermograms of VST, the two solid carriers, and optimized S-SuSMEDDS granules are shown in Figure 3B. VST has a sharp endothermic peak at about $110^{\circ} \mathrm{C}$, corresponding to its melting point and indicating its crystalline nature. There were no specific peaks for the solid carriers Florite ${ }^{\circledR}$ PS10 and Vivapur $^{\circledR} 105$. Optimized S-SuSMEDDS granules also lacked a typical VST peak, suggesting that VST exists in a solubilized and/or amorphous form in SuSMEDDS components.

\section{Development of S-SuSMEDDS tablets}

In a preliminary study, optimized S-SuSMEDDS granules were easily converted to tablet form, but this resulted in poor dissolution of less than $5 \%$ drug release after $2 \mathrm{~h}$, with no disintegration. This may be attributable to the high hardness of the tablet induced by the inclusion of Vivapur ${ }^{\circledR} 105$, which is often regarded as one of the best binders for direct compression $[5,24]$. Our previous effort to convert optimized S-SuSMEDDS granules to tablet form, without the use of Vivapur ${ }^{\circledR}$ 105 , was unfortunately unsuccessful due to the low hardness, the sticking phenomenon, or a combination of both.

To reduce disintegration time and improve the dissolution of VST, superdisintegrants can be used in tablet development. In comparison to conventional disintegrants, superdisintegrants such as CS, KC, and SSG show good disintegration action at low concentrations, ensuring fragmentation of the tablet dosage form upon ingestion and allowing the onset of drug dissolution and eventual absorption [25]. It is important to determine the most suitable superdisintegrants for the S-SuSMEDDS tablet preparation. The main mechanisms for disintegration differ: swelling for SSG [26]; swelling, wicking, and strain recovery for CS [27]; and wicking followed by secondary swelling for $\mathrm{KC}[28,29]$.

However, regardless of superdisintegrant type, compression force may affect disintegration performance of the S-SuSMEDDS formulation. Several studies reported that high compression force increased tablet hardness, resulting in an increase in disintegration time [14-16]. This may be due to the effect of compression force on tablet porosity. High compression force decreases intermolecular voids and increases inter-particle bonding and tablet densification, potentially inducing increased tablet hardness and tensile strength [30]. Thus, when considering these factors, the inclusion of compression force, and superdisintegrant concentration and type, in the optimization process was necessary for successful development of tablet dosage forms.

\section{Experimental design of S-SuSMEDDS tablets}

3-LFD was applied to determine the optimal composition of superdisintegrant and compression force, 
Table 4: Summary of the results of statistical analyses and model equations for the measured responses

\begin{tabular}{|c|c|c|c|c|c|c|}
\hline Models & Sequential p-value & $\begin{array}{c}\text { Lack of fit } \\
\text { p-value }\end{array}$ & SD & $\mathbf{R}^{2}$ & Adjusted R ${ }^{2}$ & Remark \\
\hline \multicolumn{7}{|c|}{ (A) Optimized S-SuSMEDDS granules } \\
\hline \multicolumn{7}{|c|}{$\operatorname{CSR}\left(\mathrm{Y}_{1} ; \mathrm{g} / \mathrm{mL}\right)$} \\
\hline Linear & $<0.0001$ & 0.4495 & 0.023 & 0.9985 & 0.9983 & Suggested \\
\hline Quadratic & 0.2599 & 0.4751 & 0.022 & 0.9989 & 0.9984 & - \\
\hline Cubic & 0.1940 & 0.8154 & 0.019 & 0.9993 & 0.9988 & - \\
\hline \multicolumn{7}{|l|}{$\mathrm{D}_{15}\left(\mathrm{Y}_{2} ; \%\right)$} \\
\hline Linear & $<0.0001$ & 0.3206 & 1.00 & 0.9818 & 0.9788 & Suggested \\
\hline Quadratic & 0.5592 & 0.2389 & 1.05 & 0.9831 & 0.9764 & - \\
\hline Cubic & 0.2133 & 0.2487 & 0.95 & 0.9809 & 0.9458 & - \\
\hline \multicolumn{7}{|c|}{ (B) Optimized S-SuSMEDDS tablets } \\
\hline \multicolumn{7}{|c|}{ Hardness $\left(\mathrm{Y}_{1} ; \mathrm{N}\right)$} \\
\hline Linear & 0.6210 & 0.1014 & 7.24 & 0.0964 & -0.0482 & - \\
\hline $2 \mathrm{FI}$ & 0.8409 & 0.0825 & 7.72 & 0.1791 & -0.1903 & - \\
\hline Quadratic & 0.0008 & 0.2022 & 5.46 & 0.6306 & 0.4049 & Suggested \\
\hline Cubic & 0.1307 & 0.2952 & 4.45 & 0.8634 & 0.6037 & Aliased \\
\hline \multicolumn{7}{|c|}{$\operatorname{Disint} \%\left(\mathrm{Y}_{2} ; \%\right)$} \\
\hline Linear & $<0.0001$ & 0.0377 & 10.19 & 0.8926 & 0.8754 & - \\
\hline $2 \mathrm{FI}$ & 0.0703 & 0.0519 & 8.98 & 0.9333 & 0.9032 & - \\
\hline Quadratic & 0.0046 & 0.1008 & 7.02 & 0.9633 & 0.9409 & Suggested \\
\hline Cubic & 0.0001 & 0.8308 & 2.59 & 0.9972 & 0.9919 & Aliased \\
\hline \multicolumn{7}{|l|}{$\mathrm{DE}\left(\mathrm{Y}_{3} ; \%\right)$} \\
\hline Linear & $<0.0001$ & 0.0459 & 5.15 & 0.8893 & 0.8716 & - \\
\hline $2 \mathrm{FI}$ & 0.1163 & 0.0577 & 4.69 & 0.9267 & 0.8937 & - \\
\hline Quadratic & 0.0046 & 0.1113 & 3.66 & 0.9597 & 0.9350 & Suggested \\
\hline Cubic & 0.0003 & 0.7769 & 1.48 & 0.9964 & 0.9895 & Aliased \\
\hline \multicolumn{7}{|c|}{ Total mass $\left(\mathrm{Y}_{4} ; \mathrm{mg}\right)$} \\
\hline Linear & $<0.0001$ & 0.4017 & 1.71 & 0.9777 & 0.9675 & Suggested \\
\hline $2 \mathrm{FI}$ & 0.2150 & 0.4411 & 1.62 & 0.9840 & 0.9596 & - \\
\hline Quadratic & 0.5866 & 0.4168 & 1.66 & 0.9849 & 0.9518 & - \\
\hline Cubic & 0.7812 & 0.2969 & 1.84 & 0.9896 & 0.8594 & Aliased \\
\hline
\end{tabular}

Abbreviations:SD, standard deviation; $\mathrm{R}^{2}$, squared correlation coefficient; S-SuSMEDDS, solidified supersaturable selfmicroemulsifying drug delivery system; CSR, critical solidifying ratio; $\mathrm{D}_{15}$, percentage of drug released in 15 min; Disint $\%$, percentage disintegration in $30 \mathrm{~min}$; DE, dissolution efficiency.

to promote disintegration and drug dissolution in the optimized S-SuSMEDDS tablets. Compression force $\left(\mathrm{X}_{1} ; \mathrm{kgf}\right)$ and superdisintegrant concentration $\left(\mathrm{X}_{2} ; \mathrm{wt} \%\right.$ of S-SuSMEDDS granule) were chosen as numeric independent variables, while superdisintegrant type $\left(\mathrm{X}_{3}\right)$ was selected as a categoric independent variable, as listed in Table 2. Hardness $\left(\mathrm{Y}_{1} ; \mathrm{N}\right)$ was introduced as a response variable to evaluate suitability of the formulation for tablet dosage form. The percentage of disintegration in $30 \mathrm{~min}$ (Disint $\left.\%, \mathrm{Y}_{2} ; \%\right)$ and DE $\left(\mathrm{Y}_{3} ; \%\right)$ were established as response variables to determine disintegration capacity, in order to improve drug dissolution. Total mass $\left(\mathrm{Y}_{4}\right.$; 
Table 5: Experimental and predicted values for the optimized S-SuSMEDDS granules and tablets

\begin{tabular}{lllcccc}
\hline Type & Composition & Response & Importance & $\begin{array}{c}\text { Predicted } \\
\text { value }\end{array}$ & $\begin{array}{c}\text { Experimental } \\
\text { value }\end{array}$ & $\begin{array}{c}\text { Percentage } \\
\text { prediction } \\
\text { error }^{\mathrm{a}}\end{array}$ \\
\hline $\begin{array}{l}\text { Optimized } \\
\text { S-SuSMEDDS }\end{array}$ & $\mathrm{X}_{1}: 53 \%$ & $\mathrm{Y}_{1}(\mathrm{~mL} / 100 \mathrm{~g})$ & + & 1.07 & $1.0 \pm 0.2$ & -7.0 \\
granules & $\mathrm{X}_{2}: 47 \%$ & $\mathrm{Y}_{2}(\%)$ & + & 54.6 & $58.6 \pm 2.2$ & 6.8 \\
& $\mathrm{X}_{1}: 536 \mathrm{kgf}$ & $\mathrm{Y}_{1}(\mathrm{~N})$ & - & 73.4 & $76.6 \pm 3.5$ & 4.2 \\
Optimized & $\mathrm{X}_{2}: 6.9 \%$ & $\mathrm{Y}_{2}(\%)$ & ++ & 98 & $94.3 \pm 5.6$ & -3.8 \\
$\begin{array}{l}\text { S-SuSMEDDS } \\
\text { tablets }\end{array}$ & $\mathrm{X}_{3}: \mathrm{CS}$ & $\mathrm{Y}_{3}(\%)$ & +++ & 36.1 & $38.5 \pm 1.8$ & 6.2 \\
& & $\mathrm{Y}_{4}(\mathrm{mg})$ & + & 485.8 & $489.4 \pm 2.6$ & 0.7 \\
\hline
\end{tabular}

${ }^{a}$ Calculated using the formula ([experimental value - predicted value]/experimental value $) \times 100(\%)$. Values are presented as the mean $\pm \mathrm{SD}(\mathrm{n}=3)$.

Abbreviations: S-SuSMEDDS, solidified supersaturable self-microemulsifying drug delivery system; CS, croscarmellose sodium.
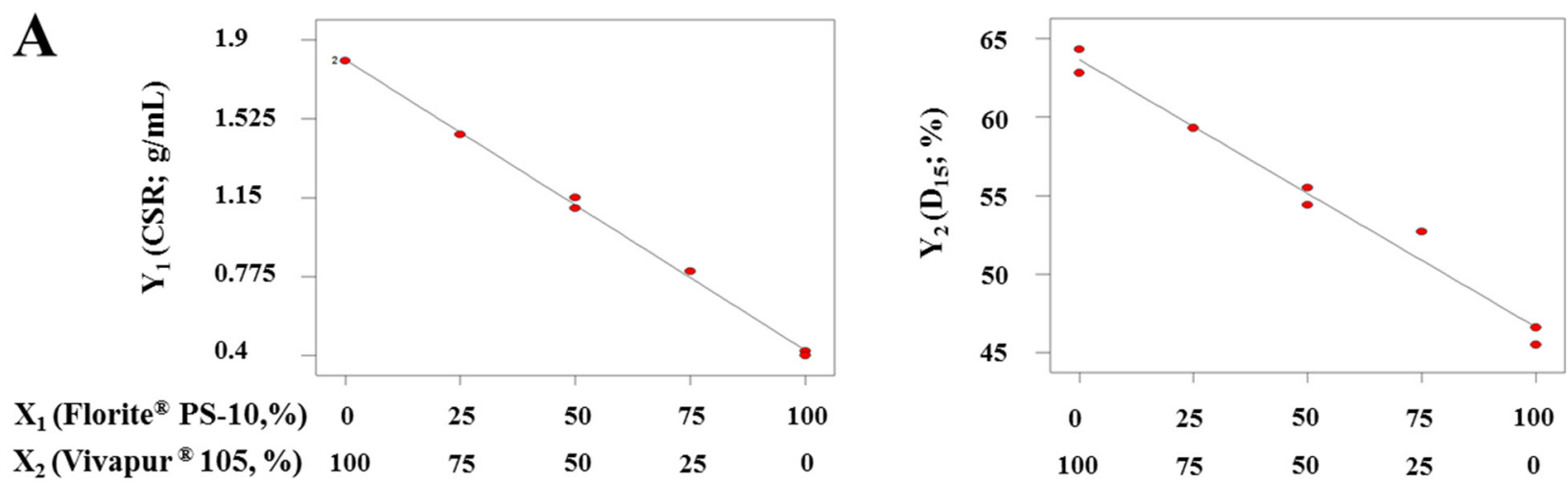

B

$\mathrm{X}_{3}$ (Type of superdisintegrant)

$\longrightarrow \mathrm{CS} \longrightarrow \mathrm{KC} \longrightarrow \mathrm{SSG}$
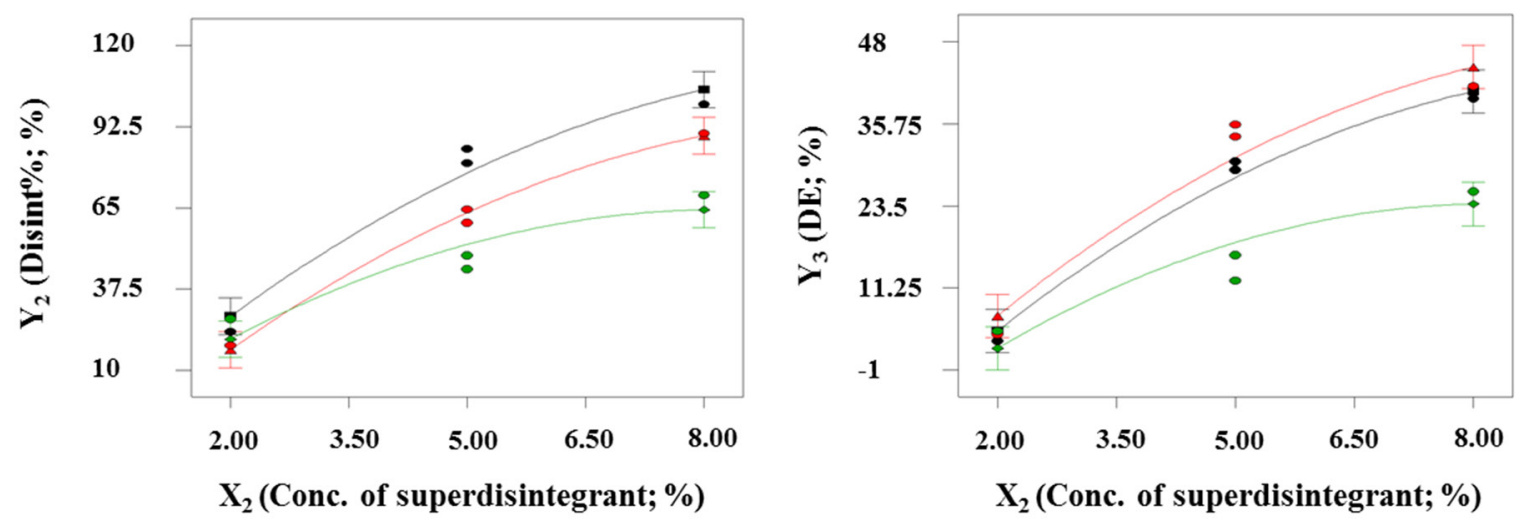

Figure 2: Effect of variables on responses for developing optimized S-SuSMEDDS granules and tablets. (A) For optimizing the S-SuSMEDDS granules: two-component mixture plots for the effect of variables $\left(\mathrm{X}_{1}\right.$ and $\left.\mathrm{X}_{2}\right)$ on responses $\mathrm{Y}_{1}$ and $\mathrm{Y}_{2}$. (B) For optimizing the S-SuSMEDDS tablets: interaction plots for the effect of variables $\left(\mathrm{X}_{2}\right.$ and $\left.\mathrm{X}_{3}\right)$ on responses $\mathrm{Y}_{2}$ and $Y_{3}$ with a fixed $X_{1}$ value $(1250 \mathrm{kgf})$. 
mg) was chosen as an additional response variable to satisfy the goal of minimizing S-SuSMEDDS tablet mass. As shown in Table 3, for the 30 experimental runs, $Y_{1}$, $\mathrm{Y}_{2}$, and $\mathrm{Y}_{3}$ were observed to be in the ranges of 66-93 N, 16.9-100.0\%, and 461.3-493.8 mg, respectively. Statistical parameters analyzed using Design Expert software are listed in Table 4. The quadratic model was suggested as the best fitting mathematical model for $\mathrm{Y}_{1}$,
$\mathrm{Y}_{2}$, and $\mathrm{Y}_{3}$ by comparing several statistical parameters. $\mathrm{Y}_{4}$ was selected for the linear model. The responses of $Y_{2}, Y_{3}$, and $\mathrm{Y}_{4}$ showed reasonably suitable statistical parameters, including $\mathrm{p}$-values $<0.05$, lack of fit $\mathrm{p}$-values $>0.1$, and $\mathrm{R}^{2}>0.95$, indicating significant model terms and accurate, reliable model fit. However, $\mathrm{R}^{2}$ value of 0.6306 was obtained for $\mathrm{Y}_{1}$ using the suggested model, indicating unsatisfactory analysis. Therefore, the model fit of $Y_{1}$ may

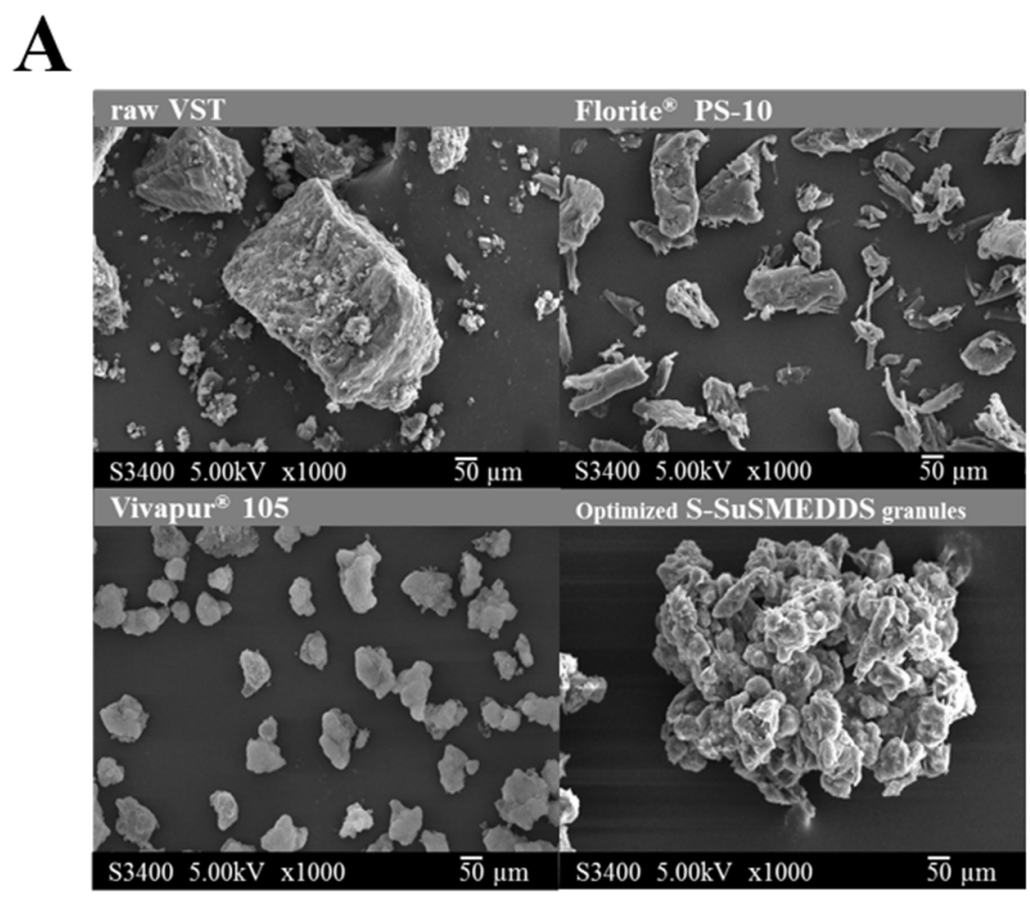

B

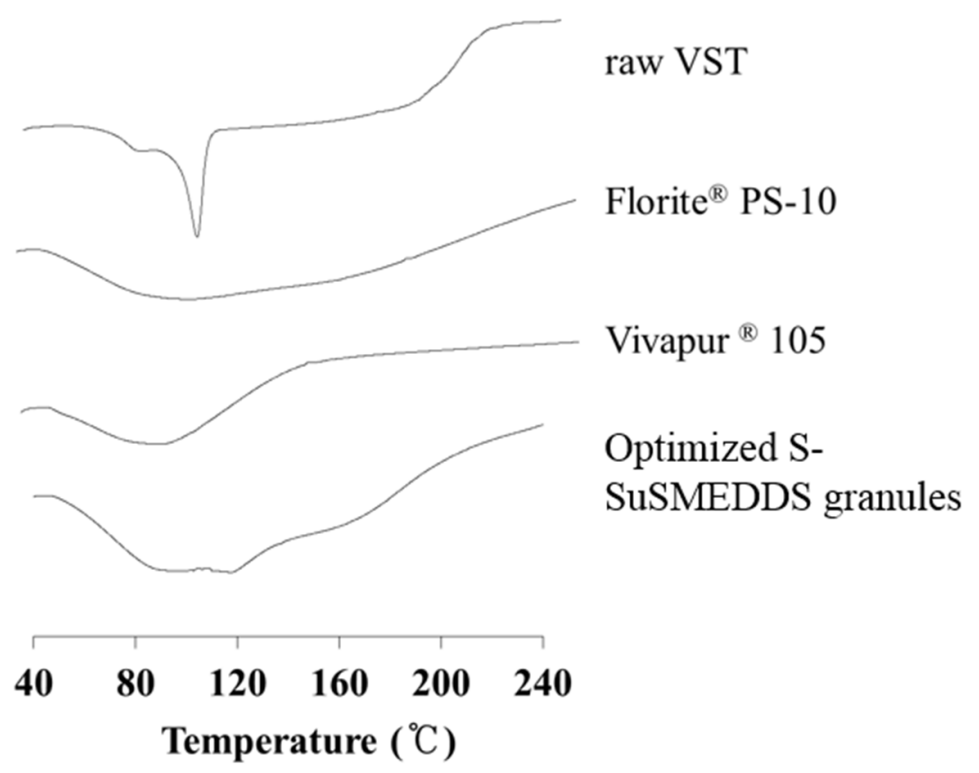

Figure 3: Solid-state properties of raw VST, solid carriers (Florite ${ }^{\circledR}$ PS-10 and Vivapur ${ }^{\circledR}$ 105), and VST-loaded optimized S-SuSMEDDS granules. (A) Scanning electron microscopic images. (B) Differential scanning calorimetric thermograms. 
Table 6: Analysis of variance for quadratic model of the measured responses for developing an optimized S-SuSMEDDS tablet

\begin{tabular}{|c|c|c|c|c|c|c|c|}
\hline \multirow[t]{2}{*}{ Source } & \multirow[t]{2}{*}{ DF } & \multicolumn{3}{|c|}{$Y_{2}($ Disint $\%)$} & \multicolumn{3}{|c|}{$Y_{3}(D E)$} \\
\hline & & SS & $\mathbf{F}$ & p-value & SS & $\mathbf{F}$ & p-value \\
\hline Model & 11 & 2115.85 & 42.99 & $<0.0001$ & 5748.42 & 38.98 & $<0.0001$ \\
\hline $\mathrm{X}_{1}$ & 1 & 10.73 & 0.22 & 0.6461 & 0.2 & 0.015 & 0.904 \\
\hline $\mathrm{X}_{2}$ & 1 & 18622.53 & 378.36 & $<0.0001$ & 4452.53 & 331.85 & $<0.0001$ \\
\hline $\mathrm{X}_{3}$ & 2 & 1466.2 & 29.79 & $<0.0001$ & 874.11 & 32.57 & $<0.0001$ \\
\hline $\mathrm{X}_{1} \mathrm{X}_{2}$ & 1 & 0.07 & 0.001 & 0.9703 & 0.24 & 0.018 & 0.8949 \\
\hline $\mathrm{X}_{1} \mathrm{X}_{3}$ & 2 & 10.62 & 0.22 & 0.808 & 0.84 & 0.031 & 0.9692 \\
\hline $\mathrm{X}_{2} \mathrm{X}_{3}$ & 2 & 480.4 & 9.76 & 0.0013 & 222.91 & 8.31 & 0.0028 \\
\hline $\mathrm{X}_{1}^{2}$ & 1 & 3.17 & 0.064 & 0.8025 & 5.17 & 0.39 & 0.5425 \\
\hline $\mathrm{X}_{2}^{2}$ & 1 & 719.15 & 14.61 & 0.0012 & 176.84 & 13.18 & 0.0019 \\
\hline Residual & 18 & 885.95 & & & 241.51 & & \\
\hline Lack of fit & 15 & 852.95 & 5.17 & 0.1008 & 231.83 & 4.79 & 0.1113 \\
\hline Pure error & 3 & 33 & & & 99.69 & & \\
\hline Corrected total & 29 & 24160.32 & & & 5989.93 & & \\
\hline
\end{tabular}

Abbreviations:DF, degrees of freedom; SS, sum of squares; S-SuSMEDDS, solidified supersaturable self-microemulsifying drug delivery system; Disint $\%$, percentage disintegration in 30 min; DE, dissolution efficiency.

potentially have little impact on the optimization process. Results of the multiple linear regression analyses for each response variable were derived using the best fitting models as follows:

$$
\begin{aligned}
& Y_{1}(C S)=68.24+0.04 X_{1}-2.53 X_{2}+0.0004 X_{1} X_{2} \\
& -0.00002 X_{1}^{2}+0.13 X_{2}^{2} \\
& Y_{1}(K C)=58.71+0.04 X_{1}-1.03 X_{2}+0.0004 X_{1} X_{2} \\
& -0.00002 X_{1}^{2}+0.13 X_{2}^{2} \\
& Y_{1}(S S G)=57.85+0.04 X_{1}-1.19 X_{2}+0.0004 \\
& X_{1} X_{2}-0.00002 X_{1}^{2}+0.13 X_{2}^{2} \\
& Y_{2}(C S)=-19.22+0.004 X_{1}+11.62 X_{2}-0.00006 \\
& X_{1} X_{2}-0.000002 X_{1}^{2}-0.56 X_{2}^{2} \\
& Y_{2}(\mathrm{KC})=-16.65+0.004 X_{1}+11.85 X_{2}-0.00006 \\
& X_{1} X_{2}-0.000002 X_{1}^{2}-0.56 X_{2}^{2} \\
& Y_{2}(S S G)=-17.10+0.004 X_{1}+9.25 X_{2}-0.00006 \\
& X_{1} X_{2}-0.000002 X_{1}^{2}-0.56 X_{2}^{2} \\
& Y_{3}(C S)=-19.23+0.004 X_{1}+11.62 X_{2}-0.00006 \\
& X_{1} X_{2}-0.000002 X_{1}^{2}-0.56 X_{2}^{2} \\
& Y_{3}(K C)=-16.65+0.004 X_{1}+11.85 X_{2}-0.00006 \\
& X_{1} X_{2}-0.000002 X_{1}^{2}-0.56 X_{2}^{2} \\
& Y_{3}(S S G)=-17.1+0.004 X_{1}+9.25 X_{2}-0.00006 \\
& X_{1} X_{2}-0.000002 X_{1}^{2}-0.56 X_{2}^{2} \\
& Y_{4}(C S / K C / S S G)=454+0.001 X_{1}+4.44 X_{2} \\
& \text { Results of analysis of variance for the responses } Y_{2} \\
& \text { and } Y_{3} \text { are listed in Table } 6 . P \text {-values of }>0.05 \text { for } X_{1} \text {, } \\
& X_{1} X_{2}, X_{1} X_{3} \text {, and } X_{1}^{2} \text { indicated that } X_{1} \text { had an insignificant } \\
& \text { effect on } Y_{2} \text { and } Y_{3} \text {. In the } S-S u S M E D D S \text { formulation, } \\
& \text { compression force was shown to have little influence } \\
& \text { on disintegration performance and drug dissolution. } \\
& \text { The porosity of solid carriers may be mostly negated }
\end{aligned}
$$

due to absorption of the liquid formulation, leading to the diminished effect of compression force. However, p-values of $<0.05$ for $\mathrm{X}_{2}, \mathrm{X}_{3}, \mathrm{X}_{2} \mathrm{X}_{3}$, and $\mathrm{X}_{2}^{2}$ indicated that $\mathrm{X}_{2}$ and $\mathrm{X}_{3}$ had significant effects on $\mathrm{Y}_{2}$ and $\mathrm{Y}_{3}$. Figure $2 \mathrm{~B}$ represents the effects of varying superdisintegrant concentration $\left(\mathrm{X}_{2}\right)$ and type $\left(\mathrm{X}_{3}\right)$ with a fixed value of $\mathrm{X}_{1}$. Disint $\%\left(\mathrm{Y}_{2}\right)$ increased from $16.8 \%$ to $100.0 \%$ as $\mathrm{X}_{2}$ increased and $\mathrm{X}_{3}$ changed. The increment of Disint $\%$ was in the order of CS $>\mathrm{KC}>\mathrm{SSG}$. This suggested that the wicking mechanism utilized by $\mathrm{CS}$ and $\mathrm{KC}$ was more favorable for disintegration of the S-SuSMEDDS tablets than the swelling mechanism proposed for SSG. Swelling is related to dimensional amplification, where particles extend omni-directionally to push apart the adjoining components and progress the degradation of the tablet matrix, while wicking is defined as a process of liquid entry by capillarity into micro-structured crevices within the tablet matrix [31, 32]. Tablet porosity contributes considerably to the performance of swelling disintegrants [25]. The porous structure of the S-SuSMEDDS filled with liquid formulation may hinder liquid entry and prolong disintegration time. However, wicking may induce water imbibition within the S-SuSMEDDS tablet, resulting in rapid desorption of the components and an increase in disintegration performance. S-SuSMEDDS tablets with added CS showed better disintegration performance than S-SuSMEDDS tablets with added KC. Wicking and swelling are recognized as the probable disintegration mechanisms for both CS and $\mathrm{KC}$, while strain recovery is proposed to be utilized only by CS [27-29]. This indicates 
that strain recovery may enhance the disintegration performance of S-SuSMEDDS tablets. Strain recovery is a reversible viscoelastic process of deformation: upon contact of compacted tablets with aqueous media, this process allows mechanical activation of disintegrant polymer chains which may assist in partial recovery of their original shapes [33]. In addition, DE $\left(\mathrm{Y}_{3}\right)$ increased from $3.1 \%$ to $42.8 \%$ as $\mathrm{X}_{2}$ increased and $\mathrm{X}_{3}$ altered. Consistent with Disint\%, both S-SuSMEDDS with added $\mathrm{CS}$ and S-SuSMEDDS tablets with added KC showed significantly higher DE values than S-SuSMEDDS tablets with added SSG. However, the difference in DE values between formulations with added $\mathrm{KC}$ and $\mathrm{CS}$ was insignificant.

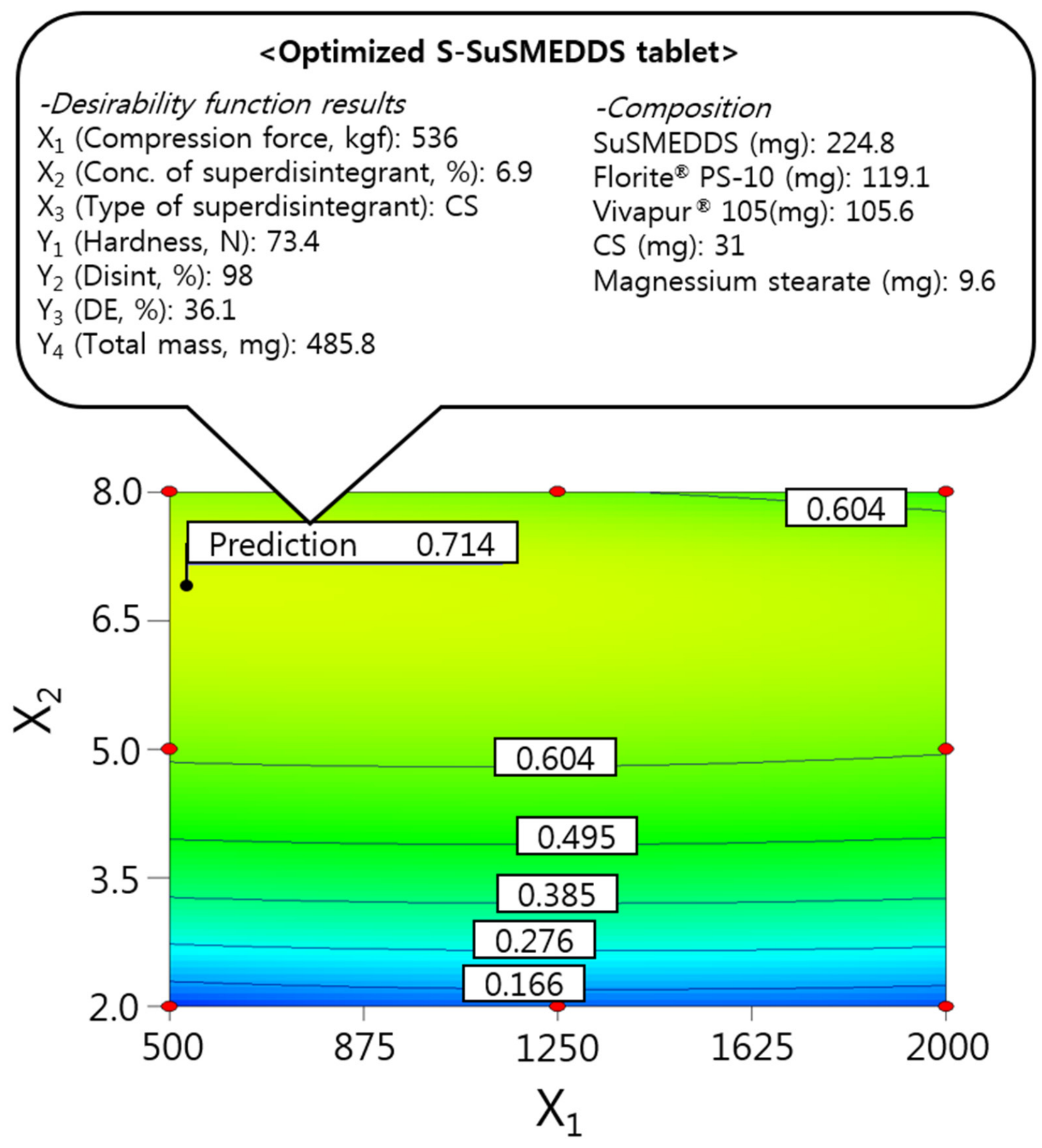

Figure 4: Overlay plot of the optimized S-SuSMEDDS tablet. Values in contour lines represent the desirability. 


\section{Optimization of S-SuSMEDDS tablets using the desirability function}

The independent variables were simultaneously optimized for responses using the desirability function. As shown in Table 2, $\mathrm{Y}_{1}$ was set at $>50 \mathrm{~N}$ for good hardness, $\mathrm{Y}_{2}$ and $\mathrm{Y}_{3}$ were maximized to improve oral absorption of VST, and $\mathrm{Y}_{4}$ was minimized to reduce the mass of individual S-SuSMEDDS tablets. Dependent variables were then ordered by importance $\left(\mathrm{Y}_{3}>\mathrm{Y}_{2}>\right.$ $\mathrm{Y}_{4}($ Table 5)), to achieve optimal desirability. Optimized compression force $\left(\mathrm{X}_{1}\right)$, superdisintegrant concentration $\left(\mathrm{X}_{2}\right)$, and superdisintegrant type $\left(\mathrm{X}_{3}\right)$ were $536 \mathrm{kgf}, 6.9 \%$, and CS, respectively, with a corresponding desirability value of 0.714 . The correlating predicted responses were $73.4 \mathrm{~N}\left(\mathrm{Y}_{1}\right), 98 \%\left(\mathrm{Y}_{2}\right), 36.1 \%\left(\mathrm{Y}_{3}\right)$, and $485.8 \mathrm{mg}\left(\mathrm{Y}_{4}\right)$. When equal importance was assigned to all responses, the corresponding desirability value decreased to 0.617 , with predicted responses of $73.3 \mathrm{~N}\left(\mathrm{Y}_{1}\right), 87 \%\left(\mathrm{Y}_{2}\right), 30.8 \%$ $\left(\mathrm{Y}_{3}\right)$, and $480.9 \mathrm{mg}\left(\mathrm{Y}_{4}\right)$. Optimization with the inclusion of varying levels of importance resulted in significantly higher desirability values, compared with those obtained by performing optimization with responses of equal importance. This suggests that S-SuSMEDDS tablets were successfully optimized, using suitable desirability functions. Consequently, as depicted in Figure 4, the final optimized S-SuSMEDDS tablet was composed of VST-loaded SuSMEDDS (224.8 mg), Florite $^{\circledR}$ PS-10 (119.1 mg), Vivapur ${ }^{\circledR} 105$ (105.6 mg), croscarmellose sodium $(31 \mathrm{mg})$, and magnesium stearate $(9.6 \mathrm{mg})$. Meanwhile, the percentage prediction errors associated with optimized S-SuSMEDDS tablets were low $(<10 \%)$, indicating accuracy and reliability of the 3-LFD. Physical properties of the optimized S-SuSMEDDS tablets were evaluated to evaluate preparation success. Drug content was in the range of 94.6-96.1\%; tablet diameter and thickness variation was within $5 \%$ of the total weight; friability was in the range of $0.07-0.13 \%$, and the weight loss of $<1 \%$ observed in the friability test was generally acceptable [22]. These results indicate that optimized S-SuSMEDDS tablets were prepared successfully using 3-LFD.

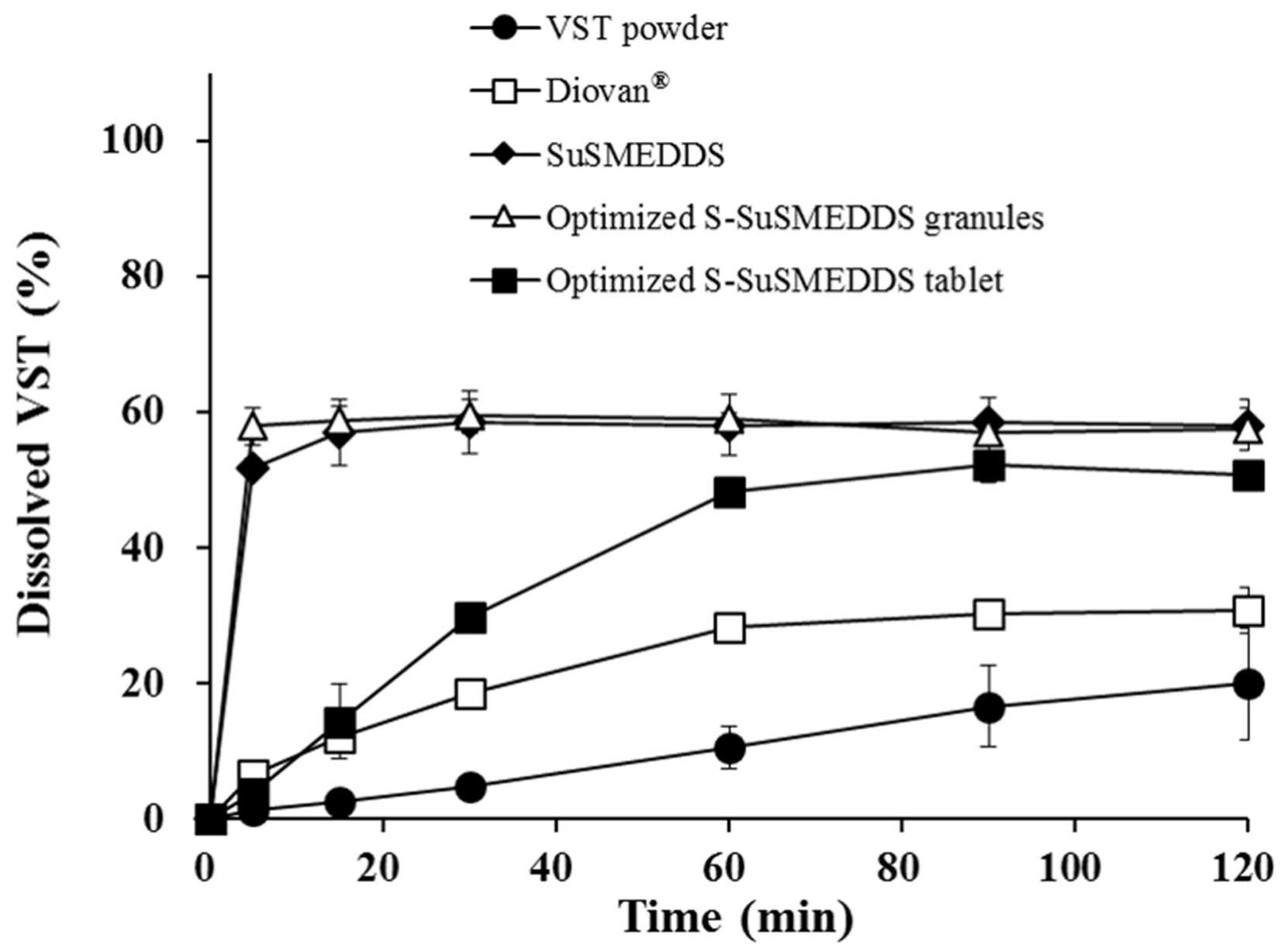

Figure 5: Dissolution profiles of various formulations containing the equivalent of $80 \mathrm{mg}$ VST in pH $1.2 \mathrm{medium}$. Values are presented as the mean $\pm \mathrm{SD}(\mathrm{n}=3)$. 
Table 7: Pharmacokinetic parameters of VST in different formulations in rats

\begin{tabular}{lccc}
\hline Parameters & Diovan $^{\circledR}$ powder & SuSMEDDS & $\begin{array}{c}\text { Optimized S-SuSMEDDS } \\
\text { granules }\end{array}$ \\
\hline $\mathrm{AUC}_{0-12}(\mathrm{ng} \cdot \mathrm{h} / \mathrm{mL})$ & $5561.5 \pm 2883.4$ & $11463.3 \pm 4523.1^{*}$ & $12350.5 \pm 3774.5^{*}$ \\
$\mathrm{C}_{\max }(\mathrm{ng} / \mathrm{mL})$ & $849.3 \pm 476.5$ & $3120.6 \pm 2367.7^{*}$ & $3337.9 \pm 1396.6^{*}$ \\
$\mathrm{~T}_{\max }(\mathrm{h})$ & $0.93 \pm 0.60$ & $1.17 \pm 0.66$ & $0.63 \pm 0.51$ \\
$\mathrm{RBA}(\%)$ & - & 206.1 & 222.1 \\
$v s$. Diovan & & - & 107.7 \\
$v s$. SuSMEDDS $^{\circledR}$ & - & - & \\
\hline
\end{tabular}

*Significantly different at $p<0.05$ versus Diovan ${ }^{\circledR}$ powder. Values are presented as the mean \pm SD $(n=6-7)$.

Abbreviations:VST, valsartan; S-SuSMEDDS, solidified supersaturable self-microemulsifying drug delivery system; $\mathrm{AUC}$, area under the curve; $\mathrm{C}_{\max }$, peak plasma concentration; $\mathrm{T}_{\max }$, time to peak plasma; $\mathrm{RBA}$, relative bioavailability; SuSMEDDS, supersaturable self-microemulsifying drug delivery system.

\section{In vitro dissolution profiles}

Dissolution profiles were determined for VST in various formulations, including VST powder, a

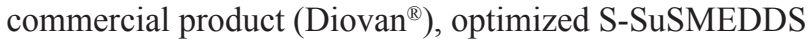
granules, and optimized S-SuSMEDDS tablets, in pH 1.2 medium over a $2 \mathrm{~h}$ period (Figure 5). During this period, dissolution of VST powder and Diovan ${ }^{\circledR}$ gradually increased to approximately $20 \%$ and $30 \%$, respectively. Fast dissolution was observed for optimized S-SuSMEDDS granules, with up to $60 \%$ of the total VST content released in the initial $5 \mathrm{~min}$. These data indicated that components of the SuSMEDDS were rapidly desorbed from Florite ${ }^{\circledR}$ PS-10 and Vivapur ${ }^{\circledR} 105$, forming microemulsions which enhanced the dissolution of VST. However, optimized S-SuSMEDDS tablets showed an

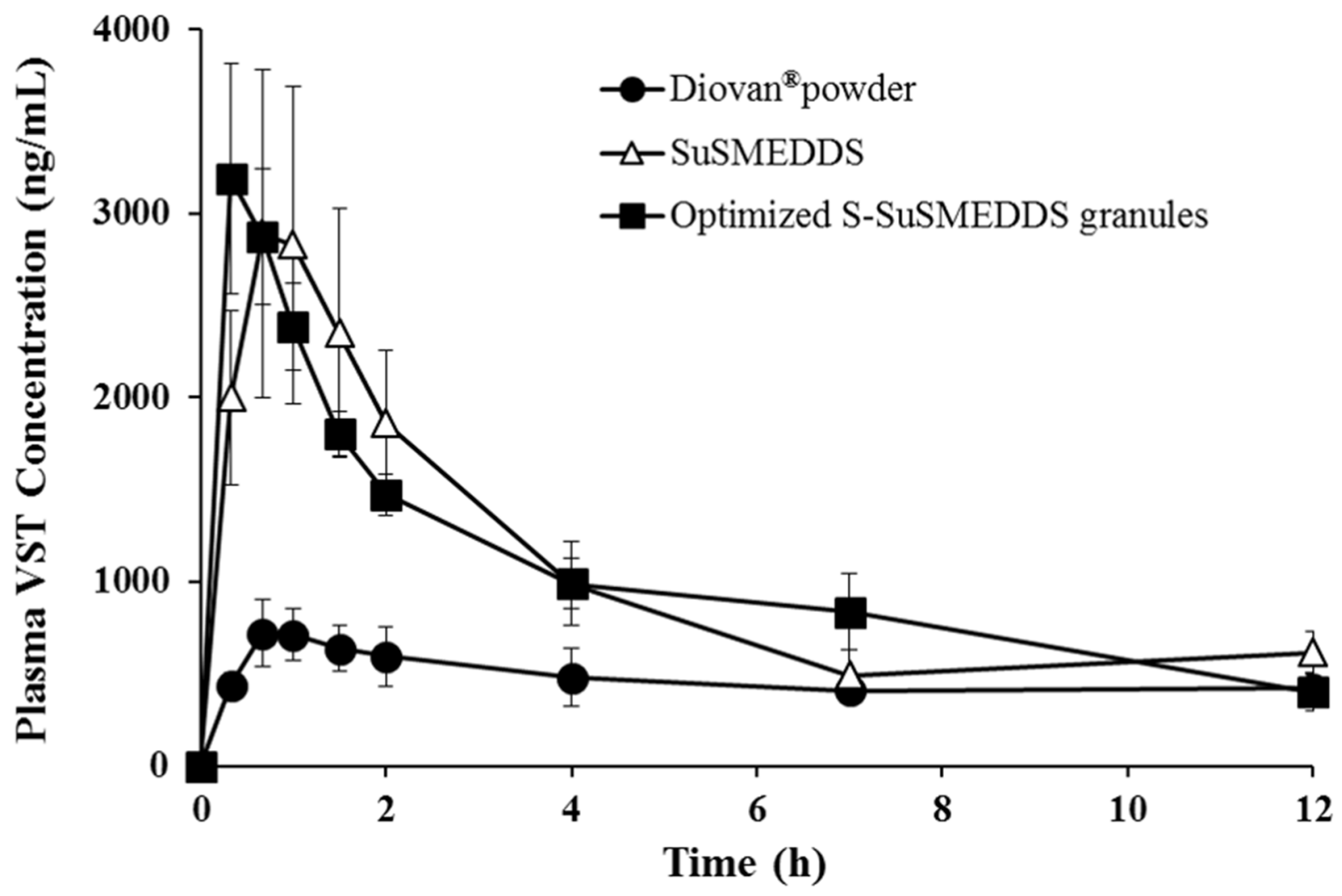

Figure 6: Plasma concentration profiles in rats after oral administrations of various formulations containing an equivalent dose of $10 \mathrm{mg} / \mathbf{k g}$ of VST. Values are presented as mean \pm standard error $(\mathrm{n}=6-7)$. 
unexpectedly gradual increase in dissolution, resulting in a plateau of $>50 \%$ dissolution at $60 \mathrm{~min}$, before reaching a similar dissolution level to S-SuSMEDDS granules. Although dissolution of optimized S-SuSMEDDS tablets was slower than that of optimized S-SuSMEDDS granules, this would be unlikely to affect total VST absorption, as the drug is preferentially absorbed in both the stomach and the upper small intestine [34]. Optimized S-SuSMEDDS tablets greatly increased VST dissolution after $2 \mathrm{~h}$ by 2.5 fold and 1.6-fold, compared with raw VST powder and Diovan $^{\circledR}$, respectively, suggesting that the S-SuSMEDDS formulation in tablet dosage form would be a promising strategy for improving the solubility of drugs with a low oral bioavailability.

\section{In vivo PK behavior}

The PK behavior of VST in rats was evaluated after oral treatment with Diovan ${ }^{\circledR}$ powder, SuSMEDDS, and optimized S-SuSMEDDS granules. Plasma levels of VST were measured and plotted against time (Figure 6). Both SuSMEDDS and optimized S-SuSMEDDS granules showed greater absorption than Diovan ${ }^{\circledR}$ powder. The initial higher absorption for SuSMEDDS and optimized S-SuSMEDDS granules may be attributed to the enhancement of VST dissolution by the acidic conditions [1]. The synergistic effect of oil and surfactants contained in both SuSMEDDS and optimized S-SuSMEDDS granules could improve the oral absorption of VST in the gastric intestinal (GI) tract [35]. The oilin-water nanoemulsions produced by oil and surfactants could have an active influence on intestinal permeation of both transcellular and paracellular transport and protect the drug from enzyme degradation [36, 37]. In particular, Transutol ${ }^{\circledR} \mathrm{P}$ and Tween ${ }^{\circledR} 80$, contained in both SuSMEDDS and optimized S-SuSMEDDS granules, have been used as permeation-enhancers and/or P-glycoprotein inhibitors, to improve oral absorption of several poorly permeable drugs $[35,38]$.

PK parameters of the different formulations are listed in Table 7. The maximum plasma concentration $\left(\mathrm{C}_{\max }\right)$ and area under the curve (AUC) values of the Diovan ${ }^{\circledR}$ powder were much lower than those of SuSMEDDS and optimized S-SuSMEDDS granules. $\mathrm{C}_{\max }$ values of SuSMEDDS and optimized S-SuSMEDDS granules were 2.0 and 2.2 times higher, respectively, than that of Diovan ${ }^{\circledR}$ powder. Based on AUC values, the relative bioavailabilities (RBAs) of SuSMEDDS and optimized S-SuSMEDDS granules were 206\% and 222\%, respectively, compared to that obtained for Diovan ${ }^{\circledR}$ powder. These results indicated that both SuSMEDDS and optimized S-SuSMEDDS granules could efficiently form microemulsions in the GI tract, resulting in the enhanced oral absorption of VST. Meanwhile, the time to reach the maximum plasma concentration $\left(\mathrm{T}_{\max }\right), \mathrm{C}_{\max }$, and $\mathrm{AUC}$ values of SuSMEDDS were 1.8, 0.9, and 0.9 times greater, respectively, than those of optimized S-SuSMEDDS granules. In particular, SuSMEDDS in a gelatin capsule yielded a slower and decreased absorption profile than the optimized S-SuSMEDDS formulation, resulting in a $T_{\max }$ value of $1.17 \mathrm{~h}$. This value was greater than that found in an earlier study $(0.33 \mathrm{~h})$, in which SuSMEDDS was administered in a pre-dispersed concentrated solution [1]. This discrepancy in the rate of absorption may be due to the inability of the highly viscous mass in the gelatin capsule to instantly disperse throughout the medium. In contrast, optimized S-SuSMEDDS granules provide an increased surface area for VST dissolution, subsequently conferring a stable microenvironment for homogenous self-emulsification in the GI tract. Therefore, the optimized S-SuSMEDDS granules described here could be a practical means for developing solid dosage forms of liquefied formulations such SMEDDS and SuSMEDDS, although future PK evaluations of S-SuSMEDDS tablets in animals or human volunteers will be necessary.

\section{MATERIALS AND METHODS}

\section{Materials}

VST was supplied by Daewon Pharm. Co. Ltd. (Seoul, Korea). Diovan ${ }^{\circledR}$ tablets containing $80 \mathrm{mg}$ VST were purchased as a reference product. Transcutol ${ }^{\circledR} \mathrm{P}$ (diethylene glycol monoethyl ether) was supplied by Gattefossé (Saint Priest, France). Capmul ${ }^{\circledR}$ MCM (glyceryl caprylate/caprate) was supplied by Abitec Co. (Janesville, WI, USA). Poloxamer 407 (Pluronic ${ }^{\circledR}$ F-127) and KC were supplied by BASF (Ludwigshafen, Germany). Tween ${ }^{\circledR} 80$ and maltodextrin were purchased from Sigma-Aldrich (St. Louis, MO, USA). Sylysia ${ }^{\circledR} 350$ (porous silica) was supplied by Fuji Silysia Chemical Co., Ltd. (Aichi, Japan). Neusilin ${ }^{\circledR}$ US2 (magnesium aluminometasilicate) was supplied by Fuji Chemical Industry Company (Toyama, Japan). Florite ${ }^{\circledR}$ PS-10 (calcium silicate) was supplied by Tomita Pharmaceutical Co., Ltd. (Tokushima, Japan). Vivapur ${ }^{\circledR} 105$ (microcrystalline cellulose) was supplied by JRS Pharma (Rosenberg, Germany). Lactose monohydrate was purchased from Daejung Chemical. Co., Ltd. (Gyeonggi-do, Korea). Magnesium stearate was purchased from FACI (Genoa, Italy). HPC was purchased from Nippon Soda Co., Ltd. (Tokyo, Japan). L-HPC were supplied by Shin-Etsu Chemical Co., Ltd. (Tokyo, Japan). Starch ${ }^{\circledR} 1500$ (partially pregelatinized maize starch) was purchased from Colorcon Asia Pacific PTE. Ltd. (Gyeonggi-do, Korea). CS and SSG were purchased from DFE Pharma (Nörten-Hardenberg, Germany). High-performance liquid chromatography (HPLC)-grade acetonitrile and methanol were purchased from JT Baker (Phillipsburg, NJ, USA). All other chemicals used were of analytical grade. 


\section{Animals}

Male Sprague-Dawley rats (200-250 g, 7-9 weeks old) were purchased from Orient Bio (Gyeonggido, Korea). The rats underwent a period of fasting for approximately $12-18 \mathrm{~h}$ prior to drug treatment, with free access to water. All animal experiments were performed in accordance with the National Institute of Health (NIH) guidelines, "Principles of laboratory animal care", and were approved by the Institutional Animal Care and Use Committee of Chung-Ang University, Seoul, Korea.

\section{Preparation of SuSMEDDS formulation}

Based on our earlier report [1], a drug-free SuSMEDDS formulation was prepared by mixing oil (Capmul ${ }^{\circledR}$ MCM $13.2 \mathrm{mg}$ ), surfactant (Tween ${ }^{\circledR} 80$ $59.2 \mathrm{mg}$ ), cosurfactant (Transcutol ${ }^{\circledR}$ P $59.2 \mathrm{mg}$ ), and a supersaturating agent (Poloxamer $40713.2 \mathrm{mg}$ ). The mixture was vortexed to result in a clear homogenous solution. The VST-loaded SuSMEDDS formulation was obtained by adding $80 \mathrm{mg}$ VST to the drug-free SuSMEDDS (144.8 mg).

\section{Screening of solid carriers}

To solidify the VST-loaded SuSMEDDS, different quantities of various solid carriers were used: Sylysia ${ }^{\circledR}$ 350, Neusilin ${ }^{\circledR}$ US2, and Florite ${ }^{\circledR}$ PS-10 as silica-based adsorbents; HPC, Vivapur ${ }^{\circledR} 105$, and L-HPC as cellulosebased diluents; and lactose monohydrate, Starch ${ }^{\circledR} 1500$, and maltodextrin as saccharide-based diluents (Table 1). Solidifying behavior was determined using the levigation method as reported previously $[9,39,40]$. Solid carriers were incrementally added and blended with a fixed quantity of SuSMEDDS in a mortar, and blending was discontinued prior to the formation of a non-flowing cohesive mass. Physical properties of the solidified mass were evaluated for flow characteristics, droplet size on reconstitution, and drug contents and dissolution.

\section{Determination of flow properties}

Flow behavior of the solidified mass was evaluated using $\mathrm{CI}$, calculated using the equation: $\mathrm{CI}=[\rho$ (tapped) $\rho$ (bulk)] $100 / \rho$ (tapped), where $\rho$ (bulk) and $\rho$ (tapped) are the bulk and tapped densities, respectively [41]. Apparent bulk and tapped bulk densities were measured using the cylinder method, with a powder tester (ABD-100, Tsutsui Scientific Instruments Co. Ltd., Tokyo, Japan). Accurately weighed granule samples were poured into a cylinder and the volume was measured to obtain the apparent bulk density; separately, a sample was tapped 100 times to measure tapped bulk density. In addition, CSR $(\mathrm{g} / \mathrm{mL})$ was obtained, defined by the minimum mass (g) of solid carrier required to solidify the unit volume of SuSMEDDS, resulting in a critical constant value of $\mathrm{CI}$

\section{Reconstitution study}

Solidified mass (equivalent to $80 \mathrm{mg}$ of VST) was dispersed in $250 \mathrm{~mL}$ of distilled water (DW). The mixture was gently vortexed (EYELA, Cute Mixer CM-1000, Tokyo, Japan) and centrifuged (Micro 17TP; Hanil Science, Incheon, Korea) at 16,000 $g$ for $10 \mathrm{~min}$ to remove the water-insoluble solids. The size of dispersed droplets in the supernatant was determined using a photon correlation spectrometer (Zetasizer Nano-ZS, Malvern Instrument, Worcestershire, UK).

\section{Drug content determination}

Solidified mass $(100 \mathrm{mg})$ was dispersed in methanol $(10 \mathrm{~mL})$, mixed thoroughly, and sonicated for $30 \mathrm{~min}$ with a bath type sonicator (Model 2210, Branson Ultrasonics Co., Danbury, CT, USA) to extract VST. Samples were filtered through a membrane filter $(0.45 \mu \mathrm{m}, \mathrm{PVDF}$, Smartpor ${ }^{\circledR}$ ), and the filtrate was appropriately diluted with methanol for HPLC analysis. VST concentration was computed from the validated calibration curve of the drug in methanol $(100 \%, \mathrm{v} / \mathrm{v})$, and drug contents were expressed as percentages of the theoretical quantity.

\section{HPLC analysis of VST}

VST concentration was determined using HPLC. The HPLC system included a pump (W2690/5; Waters Corporation, Milford, MA, USA), ultraviolet detector (W2489; Waters Corporation), data station (Empower 3; Waters Corporation), and chromatographic C18 column $(250 \times 4.6 \mathrm{~mm}, 5 \mu \mathrm{m}$; Shiseido, Tokyo, Japan), maintaining a flow rate of $1.0 \mathrm{~mL}$ per minute at $25^{\circ} \mathrm{C}$. The isocratic mobile phase was composed of acetonitrile and distilled water $(60: 40[\mathrm{v} / \mathrm{v}])$. The $\mathrm{pH}$ was adjusted to 3.0 using $10 \%$ phosphoric acid. Finally, $20 \mu \mathrm{L}$ of each sample was injected into the column, and the absorbance was measured with ultraviolet detection at $247 \mathrm{~nm}$.

\section{In vitro dissolution test}

In vitro dissolution tests were performed using the USP apparatus II (paddle) method with a Vision ${ }^{\circledR}$ Classic $6^{\mathrm{TM}}$ Dissolution Tester and Vision ${ }^{\circledR}$ heater (Hanson Research, Chatsworth, CA, USA). A pH 1.2 medium was prepared by dissolving $2 \mathrm{~g}$ of sodium chloride in $7 \mathrm{~mL}$ of hydrochloric acid and diluting with DW to $1000 \mathrm{~mL}$. Each formulation, containing $80 \mathrm{mg}$ of VST, was introduced into the $\mathrm{pH} 1.2$ dissolution medium $(500 \mathrm{~mL})$ at $37 \pm$ $0.5^{\circ} \mathrm{C}$, and stirred at $100 \mathrm{rpm}$. Samples $(5 \mathrm{~mL})$ were taken at predetermined time points $(5,15,30,60,90$, and 120 $\mathrm{min})$ and filtered through a $0.45-\mu \mathrm{m}$ polyvinylidene difluoride membrane. After appropriate dilution of the filtrate with methanol, the VST concentration in each sample was assayed using HPLC as described above. For 
comparison of dissolution profiles, DE was calculated using the trapezoidal rule as follows:

$$
\mathrm{DE}(\%)=\left[\int_{\mathrm{t} 1}^{\mathrm{t} 2} \mathrm{ydt} / \mathrm{y}_{100}(\mathrm{t} 2-\mathrm{t} 1)\right] \times 100
$$

where $y$ is the percentage of dissolved product [42].

\section{Preparation and characterization of S-SuSMEDDS granules}

Based on the screening results, two solid carriers (Florite $^{\circledR}$ PS-10 and Vivapur ${ }^{\circledR}$ 105) were selected and used in the solidification process at different ratios by blending with SuSMEDDS as described above. The final mixture, a free-flowing powder with a non-greasy appearance, was passed through a $500-\mu \mathrm{m}$ sieve, and the resultant S-SuSMEDDS granules were stored at ambient temperature in an airtight container.

\section{Experimental design}

D-optimal mixture design was used to optimize the ratio of Florite ${ }^{\circledR}$ PS-10 and Vivapur ${ }^{\circledR} 105$ for preparing the S-SuSMEDDS granules. Design-Expert software version 7 (Stat-Ease Inc, Minneapolis, USA) was used for developing and evaluating experimental design. The experiment was designed using the two components as independent variables: Florite ${ }^{\circledR}$ PS-10 $\left(\mathrm{X}_{1}\right)$ and Vivapur ${ }^{\circledR}$ $105\left(\mathrm{X}_{2}\right)$ were set within ranges of $0-100 \%$. CSR $\left(\mathrm{Y}_{1}\right)$ and $\mathrm{D}_{15}\left(\mathrm{Y}_{2}\right)$ were evaluated as response variables to determine the optimal S-SuSMEDDS granule formulation, for maximal drug release with minimal quantity.

\section{Solid-state characterization}

Solid-state properties of the drug powder, solid carriers, and optimized S-SuSMEDDS granules were investigated using SEM and DSC. Morphological features of VST powder, Florite ${ }^{\circledR}$ PS-10, Vivapur ${ }^{\circledR} 105$, and VSTloaded S-SuSMEDDS granules were investigated using a scanning electron microscope (S-3400N, Hitachi, Tokyo, Japan): samples were fixed on a metal plate, sputtered for 90 s with platinum (IonSputter, E-1010, Hitachi, Tokyo, Japan), and photographed at an excitation voltage of $5 \mathrm{kV}$. DSC measurements were performed using a DSC-Q20 (TA instrument, New Castle, DE, USA): samples (2-5 mg) were placed in an aluminum pan, and measurements were taken over a temperature range of $30-300{ }^{\circ} \mathrm{C}$, at a heat rate of $5{ }^{\circ} \mathrm{C} / \mathrm{min}$ under nitrogen flow $(20 \mathrm{~mL} / \mathrm{min})$.

\section{Preparation and evaluation of S-SuSMEDDS tablets}

S-SuSMEDDS granules were blended with selected superdisintegrants (CS, KC, and SSG) and lubricant (magnesium stearate) using a cube mixer (Type AR400ES, Erweka ${ }^{\circledR} \mathrm{GmbH}$, Heusenstamm, Germany) for $5 \mathrm{~min}$. The blended mixture was directly compressed into tablets on a single-punch tablet machine (HANDTAB-200, Ichihashi-
Seiki Co. Ltd., Kyoto, Japan) at a compression force of 500-2000 kgf using $12 \mathrm{~mm}$ standard circular concave punches, and the resultant S-SuSMEDDS tablets were stored at ambient temperature in an airtight container.

\section{Experimental design}

3-LFD was used to optimize the conditions for S-SuSMEDDS tablet preparation. The experiment was designed using three components as independent variables: the compression force $\left(\mathrm{X}_{1}\right)$ and concentration of superdisintegrant ( $w t \%$ of S-SuSMEDDS granules; $\mathrm{X}_{2}$ ) were used as numerical factors, and were set within ranges of 500-2000 kgf and 2-8\%, respectively; the type of superdisintegrant $\left(\mathrm{X}_{3}\right)$ was used as a categorical factor, and included CS, KC, and SSG. Tablet hardness ( $\left.\mathrm{Y}_{1}\right)$, Disint $\%$ $\left(\mathrm{Y}_{2}\right)$, DE $\left(\mathrm{Y}_{3}\right)$, and the total mass of S-SuSMEDDS tablet $\left(\mathrm{Y}_{4}\right)$ were evaluated as the response variables, to determine the optimal formulation for desirable physiochemical characteristics.

\section{Evaluation of physical strength}

Physical testing of optimized S-SuSMEDDS tablets was performed after a relaxation period of at least $24 \mathrm{~h}$. Weight-variation tests were performed with 20 individually weighed tablets using a balance (XS603S analytical balance; Mettler-Toledo, Columbus, OH, USA). The thickness and diameter of ten tablets were measured individually using Vernier calipers (CD-15APX; Mitutoyo, Kawasaki, Japan). Tablet friability was calculated as the percentage of weight loss (4 min, $25 \mathrm{rpm}, 20$ tablets) using a friability tester (PTF 20E; Pharma Test, Hainburg, Germany). A hardness tester (Smart-Test 50; Pharmatron, Solothun, Switzerland) was used to determine tablet hardness. Ten tablets from each formulation were tested.

\section{Disintegration test}

Disintegration tests were performed in $900 \mathrm{~mL}$ distilled water at $37^{\circ} \mathrm{C}$ for $30 \mathrm{~min}$ using a disintegration tester (DIT-200, Gyeonggi-do, Korea). After the disintegration test, the remaining sample was taken and dried in an oven at $40^{\circ} \mathrm{C}$ for $24 \mathrm{~h}$ to determine Disint $\%$, calculated by $100^{*}\left(\mathrm{~W}_{\mathrm{i}}-\mathrm{W}_{\mathrm{f}}\right) / \mathrm{W}_{\mathrm{i}}$, where $\mathrm{W}_{\mathrm{i}}$ and $\mathrm{W}_{\mathrm{f}}$ are the masses (mg) of samples before and after the disintegration test, respectively.

\section{In vivo oral absorption study}

\section{Oral administration and plasma sampling}

After rats had undergone overnight fasting (12-18 h), VST treatments were administered using a Torpac ${ }^{\circledR}$ Kit. Test subjects were randomly divided into three groups (n $=5-7$ ): Group 1 received Diovan ${ }^{\circledR}$ (commercial product, ground into powder), Group 2 received SuSMEDDS, Group 3 received optimized S-SuSMEDDS granules. In all treatments, a dose equivalent to $10 \mathrm{mg} / \mathrm{kg}$ VST was accurately weighed and dispensed into hard gelatin capsules (Torpac capsule size 9) (Torpac, Fairfield, NJ, 
USA) by means of a stand, funnel, and tamper (Torpac kit, Torpac). All capsules were administered directly into the stomach by using a dosing syringe plunger (Torpac kit, Torpac). Blood samples (approximately $0.3 \mathrm{~mL}$ ) were collected from the retro-orbital plexus into heparinized tubes at predetermined time points (20 and $40 \mathrm{~min}, 1,1.5$, $2,4,7,12$, and $24 \mathrm{~h}$ ) and were centrifuged at $16,000 \mathrm{~g}$ for $15 \mathrm{~min}$. Plasma samples were stored at $-80^{\circ} \mathrm{C}$ until analysis by liquid chromatography-tandem mass spectrometry (LCMS/MS).

Whole plasma samples $(50 \mu \mathrm{L})$ were mixed with $700 \mu \mathrm{L}$ of methanol and $20 \mu \mathrm{L}$ of internal standard (IS) solution $(10,000 \mathrm{ng} / \mathrm{mL}$ VST-d3 in 50\% methanol) and were vortexed for $3 \mathrm{~min}$. After centrifugation at 16,000 $g$ for $5 \mathrm{~min}, 20 \mu \mathrm{L}$ of the supernatant was carefully transferred to a test tube and was evaporated using nitrogen. The dry residue was reconstituted in $480 \mu \mathrm{L}$ of DW, and the mixture was vortexed and centrifuged at $16,000 \mathrm{~g}$ for $5 \mathrm{~min}$. Finally, $100 \mu \mathrm{L}$ of the supernatant was transferred to autosampling vials for introduction into the LC-MS/MS system.

\section{Determination of VST in plasma samples using LC- MS/MS}

Liquid chromatographic separation was performed using an Agilent 1260 autosampler (Agilent Technologies Inc, Santa Clara, CA, USA). The temperature of the autosampler was maintained at $7^{\circ} \mathrm{C}$, and $5 \mu \mathrm{L}$ of each reconstituted sample was separated into components using a Waters Atlantis dC18 column $(50 \times 2.1 \mathrm{~mm}, 3 \mu \mathrm{m}$; Milford, MA, USA) at $35^{\circ} \mathrm{C}$. An isocratic mobile phase was used, containing $10 \mathrm{mM}$ ammonium formate ( $\mathrm{pH}$ 2.7) and methanol $(20: 80,[\mathrm{v} / \mathrm{v}])$, at a flow rate of $0.3 \mathrm{~mL}$ per $\min$.

The components eluted from the column were delivered into an API 4500 triple quadrupole mass spectrometer (Applied Biosystems/MDS SCIEX, Foster City, CA, USA) with electrospray ionization in positive ion mode for ion production. The ion spray voltage was set at $5.5 \mathrm{kV}$, and the source temperature was set at $550^{\circ} \mathrm{C}$. Multiple reaction monitoring was performed using nitrogen as the collision gas. Analytes were detected by monitoring the transitions $436.2(\mathrm{Q} 1) \rightarrow 291.0(\mathrm{Q} 3)$ and $439.2(\mathrm{Q} 1) \rightarrow 294.0(\mathrm{Q} 3) \mathrm{m} / \mathrm{z}$, with a declustering potential of $28 \mathrm{~V}$ and collision energies of $23 \mathrm{~V}$, for VST and IS, respectively. Nebulizer gas (Gas 1$)$ at $40^{\circ} \mathrm{C}$ and heater gas (Gas 2) temperatures were both set at $70^{\circ} \mathrm{C}$. For quantifying VST in the plasma samples, each peak area of VST was divided by that of the internal standard, and the ratio was compared with a calibration curve obtained using VST standard solution in the same manner.

\section{PK assessment}

Data analysis was performed using the BA Calc 2007 pharmacokinetic analysis program (Ministry of Food and Drug Safety [formerly Korea Food and Drug Administration], Chungcheongbuk-do, Korea). The AUC from 0 to $24 \mathrm{~h}$ was calculated using the linear trapezoidal rule. The $\mathrm{C}_{\max }$ and $\mathrm{T}_{\max }$ were determined directly from the concentration-time data. RBA was calculated by dividing the AUCs of the test samples with those of the VST suspension.

\section{Statistical analysis}

All data are expressed as mean \pm standard deviation (SD). Statistical significance was determined using Student's $t$-test, with $p<0.05$ considered statistically significant. Design-Expert software was used to determine the simultaneously assigned statistical values of all responses.

\section{CONCLUSIONS}

Novel formulations of VST-loaded S-SuSMEDDS granules and tablets were successfully developed using D-optimal mixture design and 3-LFD, respectively, resulting in percentage prediction errors of $<10 \%$. SuSMEDDS composed of VST, Capmul ${ }^{\circledR}$ MCM, Tween ${ }^{\circledR} 80$, Transcutol ${ }^{\circledR}$ $\mathrm{P}$, and Poloxamer 407 was efficiently solidified with Florite ${ }^{\circledR}$ PS-10 and Vivapur ${ }^{\circledR} 105$, and the resultant granules showed good flow properties and rapid drug dissolution. By introducing CS as a superdisintegrant, S-SuSMEDDS tablets were successfully formulated, resulting in fast disintegration and high dissolution efficiency. In PK studies in rats, the RBA of the optimized granules was $107 \%$ and $222 \%$ of the values obtained for SuSMEDDS and Diovan ${ }^{\circledR}$ powder, respectively. Therefore, we suggest that the optimized S-SuSMEDDS formulations offer great potential for developing solid dosage forms, with improved oral absorption of poorly water-soluble drugs such as VST.

\section{Abbreviations}

3-LFD: 3-level factorial design, AUC: Area under the curve, RBA: Relative bioavailability, CI: Carr's index, $\mathrm{C}_{\text {max }}$ : Maximum plasma concentration, CS: Croscarmellose sodium, CSR: Critical solidifying ratio, $\mathrm{D}_{15}$ : Percentage of drug released in $15 \mathrm{~min}$, DE: Dissolution efficiency, Disint\%: Percentage of disintegration in $30 \mathrm{~min}$, DSC: Differential scanning calorimetry, DW: Distilled water, GI: gastric intestinal, HPC: Hydroxypropyl cellulose L type, HPLC: High-performance liquid chromatography, KC: Kollidon ${ }^{\circledR}$ CL, LC-MS/MS: Liquid chromatographytandem mass spectrometry, L-HPC: Low-substituted hydroxypropyl cellulose B1, PK: Pharmacokinetic, $\mathrm{R}^{2}$ : Squared correlation coefficient, RBA: Relate bioavailability, SEM: Scanning electron microscopy, SMEDDS: Self-microemulsifying drug delivery system, SSG: Sodium starch glycolate, S-SuSMEDDS: Solidified supersaturable self-microemulsifying drug delivery system, SuSMEDDS: Supersaturable selfmicroemulsifying drug delivery system, $\mathrm{T}_{\max }$ : Time to reach the maximum plasma concentration, VST: Valsartan. 


\section{CONFLICTS OF INTEREST}

The authors declare no disclosure of potential conflicts of interest.

\section{FUNDING}

This work was supported by the Advanced Technology Center program (10051950) funded by the Ministry of Trade, Industry \& Energy (MI, Korea).

\section{REFERENCES}

1. Yeom DW, Chae BR, Son HY, Kim JH, Chae JS, Song SH, Oh D, Choi YW. Enhanced oral bioavailability of valsartan using a polymer-based supersaturable self-microemulsifying drug delivery system. Int $\mathrm{J}$ Nanomedicine. 2017; 12: 3533-3545.

2. Wang Z, Sun J, Wang Y, Liu X, Liu Y, Fu Q, Meng P, He Z. Solid self-emulsifying nitrendipine pellets: preparation and in vitro/in vivo evaluation. Int J Pharm. 2010; 383: 1-6.

3. Chavan RB, Modi SR, Bansal AK. Role of solid carriers in pharmaceutical performance of solid supersaturable SEDDS of celecoxib. Int J Pharm. 2015; 495: 374-384.

4. Cirri M, Roghi A, Valleri M, Mura P. Development and characterization of fast-dissolving tablet formulations of glyburide based on solid self-microemulsifying systems. Eur J Pharm Biopharm. 2016; 104: 19-29.

5. Nazzal S, Nutan M, Palamakula A, Shah R, Zaghloul A, Khan M. Optimization of a self-nanoemulsified tablet dosage form of Ubiquinone using response surface methodology: effect of formulation ingredients. Int J Pharm. 2002; 240: 103-114.

6. Sermkaew N, Ketjinda W, Boonme P, Phadoongsombut $\mathrm{N}$, Wiwattanapatapee R. Liquid and solid selfmicroemulsifying drug delivery systems for improving the oral bioavailability of andrographolide from a crude extract of Andrographis paniculata. Eur J Pharm Sci. 2013; 50: 459-466.

7. Qi X, Qin J, Ma N, Chou X, Wu Z. Solid selfmicroemulsifying dispersible tablets of celastrol: Formulation development, charaterization and bioavailability evaluation. Int J Pharm. 2014; 472: 40-47.

8. Tan A, Rao S, Prestidge CA. Transforming lipid-based oral drug delivery systems into solid dosage forms: an overview of solid carriers, physicochemical properties, and biopharmaceutical performance. Pharm Res. 2013; 30: 2993-3017.

9. Yeom DW, Son HY, Kim JH, Kim SR, Lee SG, Song SH, Chae BR, Choi YW. Development of a solidified selfmicroemulsifying drug delivery system (S-SMEDDS) for atorvastatin calcium with improved dissolution and bioavailability. Int J Pharm. 2016; 506: 302-311.
10. Dangre PV, Gilhotra RM, Dhole SN. Formulation and development of solid self miro-emulsifying drug delivery system (S-SMEDDS) containing chlorthalidone for improvement of dissolution. J Pharm Invest. 2016; 46: 633-644.

11. Park JB, Choi BK, Kang CY. Effects of absorbent materials on a self-emulsifying drug delivery system for a poorly water soluble drug. J Pharm Invest. 2015; 45: 529-539

12. Rahman Z, Zidan AS, Khan MA. Risperidone solid dispersion for orally disintegrating tablet: its formulation design and non-destructive methods of evaluation. Int $\mathrm{J}$ Pharm. 2010; 400: 49-58.

13. Battu SK, Repka MA, Majumdar S, Madhusudan RY. Formulation and evaluation of rapidly disintegrating fenoverine tablets: effect of superdisintegrants. Drug Dev Ind Pharm. 2007; 33: 1225-1232.

14. Bi Y, Sunada H, Yonezawa Y, Danjo K. Evaluation of rapidly disintegrating tablets prepared by a direct compression method. Drug Dev Ind Pharm. 1999; 25: 571-581.

15. Late SG, Yu YY, Banga AK. Effects of disintegrationpromoting agent, lubricants and moisture treatment on optimized fast disintegrating tablets. Int J Pharm. 2009; 365: 4-11.

16. Schiermeier S, Schmidt PC. Fast dispersible ibuprofen tablets. Eur J Pharm Sci. 2002; 15: 295-305.

17. United States Pharmacopeia and National Formulary. USP 36-NF 31. Rockville (MD): United States Pharmacopeia Convention. 2013: p 1174 Powder Flow.

18. Teas C, Kalligeros S, Zanikos F, Stournas S, Lois E, Anastopoulos G. Investigation of the effectiveness of absorbent materials in oil spills clean up. Desalination. 2001; 140: 259-264.

19. Godec A, Maver U, Bele M, Planinšek O, Srčič S, Gaberšček M, Jamnik J. Vitrification from solution in restricted space: Formation and stabilization of amorphous nifedipine in a nanoporous silica xerogel carrier. Int $\mathrm{J}$ Pharm. 2007; 343: 131-140.

20. Planinšek O, Kovačič B, Vrečer F. Carvedilol dissolution improvement by preparation of solid dispersions with porous silica. Int J Pharm. 2011; 406: 41-48.

21. Ito Y, Kusawake T, Prasad YVR, Sugioka N, Shibata N, Takada K. Preparation and evaluation of oral solid heparin using emulsifier and adsorbent for in vitro and in vivo studies. Int J Pharm. 2006; 317: 114-119.

22. Kim S, Gupta B, Moon C, Oh E, Jeong JH, Yong CS, Kim JO. Employing an optimized spray-drying process to produce ezetimibe tablets with an improved dissolution profile. J Pharm Invest. 2016; 46: 583-592.

23. Yan YD, Sung JH, Kim KK, Kim DW, Kim JO, Lee BJ, Yong CS, Choi HG. Novel valsartan-loaded solid dispersion with enhanced bioavailability and no crystalline changes. Int J Pharm. 2012; 422: 202-210. 
24. Herting MG, Kleinebudde P. Roll compaction/dry granulation: Effect of raw material particle size on granule and tablet properties. Int J Pharm. 2007; 338: 110-118.

25. Desai PM, Liew CV, Heng PW. Review of Disintegrants and the Disintegration Phenomena. J Pharm Sci. 105: $2545-2555$

26. Augsburger LL, Brzeczko AW, Shah U, Hahm HA. Super disintegrants: characterization and function. In: Swarbrick J, ed. Encyclopedia of Pharmaceutical Technology. 3rd ed. New York, NY: Informa Healthcare USA, Inc. 2007: 3553-3567.

27. Moreton RC. Disintegrants in tableting. In: Augsburger LL, Hoag SW, eds. Pharmaceutical Dosage Forms: Tablets. 3rd ed. New York, NY: Informa Healthcare USA, Inc. 2008: 217-249.

28. Kornblum SS, Stoopak SB. A new tablet disintegrating agent: Cross-linked polyvinylpyrrolidone. J Pharm Sci. 1973; 62: 43-49.

29. Shiyani B, Gattani S, Surana S. Formulation and evaluation of bi-layer tablet of metoclopramide hydrochloride and ibuprofen. AAPS PharmSciTech. 2008; 9: 818-827.

30. Van Veen B, Van der Voort Maarschalk K, Bolhuis G, Zuurman K, Frijlink H. Tensile strength of tablets containing two materials with a different compaction behaviour. Int J Pharm. 2000; 203: 71-79.

31. De Schoenmaker B, Van der Schueren L, De Vrieze S, Westbroek P, De Clerck K. Wicking properties of various polyamide nanofibrous structures with an optimized method. J Appl Polym Sci. 2011; 120: 305-310.

32. Quodbach J, Kleinebudde P. Performance of tablet disintegrants: impact of storage conditions and relative tablet density. Pharm Dev Technol. 2015; 20: 762-768.

33. Patel S, Kaushal AM, Bansal AK. Effect of particle size and compression force on compaction behavior and derived mathematical parameters of compressibility. Pharm Res. 2007; 24: 111-124.
34. Schmidt EK, Antonin KH, Flesch G, Racine-Poon A. An interaction study with cimetidine and the new angiotensin II antagonist valsartan. Eur J Clin Pharmacol. 1998; 53: 451-458.

35. Yin YM, Cui FD, Mu CF, Choi MK, Kim JS, Chung SJ, Shim CK, Kim DD. Docetaxel microemulsion for enhanced oral bioavailability: preparation and in vitro and in vivo evaluation. J Control Release. 2009; 140: 86-94.

36. Brüsewitz C, Schendler A, Funke A, Wagner T, Lipp R. Novel poloxamer-based nanoemulsions to enhance the intestinal absorption of active compounds. Int J Parm. 2007; 329: 173-181.

37. Setthacheewakul S, Mahattanadul S, Phadoongsombut N, Pichayakorn W, Wiwattanapatapee R. Development and evaluation of self-microemulsifying liquid and pellet formulations of curcumin, and absorption studies in rats. Eur J Pharm Biopharm. 2010; 76: 475-485.

38. Takahashi Y, Kondo H, Yasuda T, Watanabe T, Kobayashi SI, Yokohama S. Common solubilizers to estimate the Caco-2 transport of poorly water-soluble drugs. Int J Pharm. 2002; 246: 85-94.

39. Mura P, Valleri M, Cirri M, Mennini N. New solid selfmicroemulsifying systems to enhance dissolution rate of poorly water soluble drugs. Pharm Dev Technol. 2012; 17: 277-284.

40. Shao A, Chen G, Jiang N, Li Y, Zhang X, Wen L, Yang F, Wei S. Development and evaluation of selfmicroemulsifying liquid and granule formulations of Brucea javanica oil. Arch Pharm Res. 2013; 36: 993-1003.

41. Shakeel F, Haq N, Alanazi FK, Alsarra IA. Polymeric solid self-nanoemulsifying drug delivery system of glibenclamide using coffee husk as a low cost biosorbent. Powder Technol. 2014; 256: 352-360.

42. Khan KA. The concept of dissolution efficiency. J Pharm Pharmacol. 1975; 27: 48-49. 